\title{
Evolution of the Corrosion Product Film and Its Effect on the Erosion- Corrosion Behavior of Two Commercial 90Cu-10Ni Tubes in Seawater
}

\author{
Okpo O. Ekerenam ${ }^{1,2} \cdot \mathrm{Ai}-\mathrm{Li} \mathrm{Ma}{ }^{1} \cdot$ Yu-Gui Zheng ${ }^{1} \cdot \mathrm{Si}-\mathrm{Yu} \mathrm{He}^{1} \cdot$ Peter C. Okafor $^{3}$
}

Received: 8 January 2018/Revised: 9 April 2018/Published online: 16 May 2018

(C) The Chinese Society for Metals and Springer-Verlag GmbH Germany, part of Springer Nature 2018

\begin{abstract}
The composition and structural evolution of the corrosion product film of two commercial $90 \mathrm{Cu}-10 \mathrm{Ni}$ tubes, namely Tube $\mathrm{A}$ and Tube B, after being immersed in natural seawater for 1,3, and 6 months were characterized by scanning electron microscopy, energy-dispersive X-ray spectroscopy, X-ray diffraction, and X-ray photoelectron spectroscopy, and its effect on the erosion-corrosion behavior of the tubes was determined through a rotating cylinder electrode system using various electrochemical techniques. For the freshly polished samples used as contrast samples, the flow velocity mainly enhanced the cathodic reaction at low flow velocities while both the anodic and the cathodic reactions were remarkably accelerated at higher flow velocities. The corrosion product films formed on the two commercial $90 \mathrm{Cu}-10 \mathrm{Ni}$ tubes after being immersed in seawater for up to 6 months are of a complex three-layer or multilayer structure. The structural evolution of the films is out of sync for the two tubes. A continuous residual substrate layer depleted of $\mathrm{Ni}$ was observed in the inner layer of the films on Tube B after 30, 90, and 180 days' immersion, while it was observed in the film on Tube A only after 180 days' immersion. The nature of the inner layer plays a crucial role in the erosion-corrosion resistance of the $90 \mathrm{Cu}-10 \mathrm{Ni}$ tubes at higher flow velocity. The film with a compact and continuous inner layer of $\mathrm{Cu}_{2} \mathrm{O}$ doped with $\mathrm{Ni}^{2+}$ and $\mathrm{Ni}^{3+}$ which bonds firmly with the substrate could survive and even get repaired with the increased flow velocity. The film on Tube B possessing a hollow and discontinuous inner layer composed of the residual substrate was degraded rapidly with increasing rotation speed in spite of its quite good resistance at the stagnant or lower speed conditions.
\end{abstract}

Keywords Copper-nickel alloy · Seawater immersion · Erosion-corrosion · Corrosion product film · Flow velocity

\section{Introduction}

Copper-nickel alloys have been extensively used in a wide range of applications in marine environment such as condensers, heat exchangers, and seawater piping in ships and desalination plants. Regardless of the emergence of some alloys with better corrosion resistance, for example,

Available online at http://link.springer.com/journal/40195

Ai-Li Ma

alma@imr.ac.cn

1 CAS Key Laboratory of Nuclear Materials and Safety Assessment, Institute of Metal Research, Chinese Academy of Sciences, Shenyang 110016, China

2 University of Chinese Academy of Sciences (UCAS), Beijing 100049, China

3 Department of Pure and Applied Chemistry, University of Calabar, PMB 1115, Calabar, CRS, Nigeria stainless steels and titanium alloys, copper-nickel alloys continue to be widely used in seawater pipelines due to their good antifouling property and good thermal conductivity $[1,2]$. There exists a range of different copper-nickel alloys possessing distinct properties and therefore suited for different applications; however, the $90 \mathrm{Cu}-10 \mathrm{Ni}$ alloy, which contains approximately $90 \%$ copper and $10 \%$ nickel, is most widely employed due to its cost-effectiveness.

The good corrosion resistance of the copper-nickel alloys to seawater is generally associated with the formation of protective corrosion product film after immersion in seawater [3-5]. As one of the earlier groups in this field, North and Pryor [6] explained the anti-corrosion advantage of the copper-nickel alloy over that of pure copper in terms of the defective semiconductor property of the $\mathrm{Cu}_{2} \mathrm{O}$ film on the copper-base alloys. They suggested that nickel and iron were incorporated into the $\mathrm{Cu}_{2} \mathrm{O}$ film formed in 3.4 $\mathrm{wt} \% \mathrm{NaCl}$ solution, occupied cation vacancies, reduced the cation vacancy concentration, and thus increased the 
corrosion resistance. Almost during the same period, Brooks found that the oxide film formed on the surface of these alloys after immersion in synthetic seawater contained an outer $\mathrm{CuO}$ porous layer with chemisorbed water molecules and traces of chloride ions, and an inner $\mathrm{Cu}_{2} \mathrm{O}$ compact layer consisting of $\mathrm{Ni}^{2+}$ and $\mathrm{Ni}^{3+}$ states [7]. Further work has also been done in the corrosion behavior of these alloys in natural seawater. Beccaria and Crousier [8] demonstrated the existence of synergistic effect between nickel and iron in $70 \mathrm{Cu}-30 \mathrm{Ni}$ alloys with iron content from $<0.05$ to $2 \%$ after immersion in quiescent natural seawater for up to 30 days. Ni incorporation into corrosion product film is found to improve corrosion resistance of copper but its effect is immensely enhanced by the presence of iron in the alloy [8]. And the correlation between the microstructure and the corrosion behavior of the $90 \mathrm{Cu}-10 \mathrm{Ni}$ alloy was attempted to be established [9]. It has since been established that a duplex layer film is formed on $\mathrm{Cu}-\mathrm{Ni}$ alloy in seawater in which corrosion resistance is attributed to a thin but compact layer of cuprous oxide $\left(\mathrm{Cu}_{2} \mathrm{O}\right)$ incorporating $\mathrm{Ni}^{+2} / \mathrm{Ni}^{+3}$ and $\mathrm{Fe}^{+3}$ underlying a thick and porous layer of cupric hydroxide/ oxide/hydroxychloride $[5,10,11]$. Not unexpectedly, the role of corrosion product film in the corrosion resistance of these alloys also received much attention. Ma et al. [12] investigated the composition and structure of the corrosion product film formed on a commercial $90 \mathrm{Cu}-10 \mathrm{Ni}$ tube after being immersed in natural seawater for 1 month and demonstrated that the surface film had immensely improved the corrosion resistance of the tube in stagnant $3.5 \mathrm{wt} \% \mathrm{NaCl}$ solution. But none of these studies has attempted to reveal the evolution of corrosion product film with a long-term immersion in natural seawater, nor has any work been focused on the influence of corrosion product film on the erosion-corrosion behavior of these alloys. However, both of the two issues are of great importance to fully understand the reason of the frequently reported corrosion failure of copper-nickel seawater tubes [13-15].

Erosion-corrosion behavior of copper-nickel alloys has received increasing attention because it is closely related to the performance and service life of copper-nickel seawater tubes in ships and other marine applications. Increase in flow velocities has been reported to have no remarkable effect on the corrosion rate until a critical velocity, also called a breakaway velocity, is reached. Syrett [16] reported the maximum flow velocity for $90 \mathrm{Cu}-10 \mathrm{Ni}$ systems to be conservatively limited to $3.5 \mathrm{~m} / \mathrm{s}$ depending on the inner pipe diameter. Complexities in the erosion-corrosion behavior of copper-nickel alloys have also been pointed out by other researchers, as demonstrated by both the unexpected decreasing trend of the polarization resistance of surface film with increasing content of $\mathrm{Ni}$ in the alloy [17] and the complicated relationship between the attack rate and the impinging velocity [18]. Thus, further data are still essential to understand the erosion-corrosion behavior of copper-nickel alloys.

In addition, the end users of $90 \mathrm{Cu}-10 \mathrm{Ni}$ tubes have reported widely varied service lives of tubes serving in flowing seawater delivered by different manufacturers. Therefore, this paper is to investigate the effect of immersion time in natural seawater on the erosion-corrosion behavior of two commercial $90 \mathrm{Cu}-10 \mathrm{Ni}$ tubes. The main focuses of this work are on the evolution of corrosion product film with immersion time in natural seawater, and also on its influence over the erosion-corrosion resistance of the tubes. The composition and structure of the surface films were examined by scanning electron microscopy assisted by energy-dispersive spectroscopy (SEM/ EDS), X-ray diffraction (XRD), and X-ray photoelectron spectroscopy (XPS). The erosion-corrosion behavior was evaluated electrochemically by open-circuit potential (OCP), polarization, and electrochemical impedance spectroscopy (EIS) measurements. The correlation between the evolution of corrosion product film and the erosioncorrosion resistance was discussed.

\section{Experimental}

\subsection{Materials}

The experimental materials are two commercial 90copper10nickel alloy tubes, designated as Tube A and Tube B, respectively, delivered by two different manufacturers with the same external diameter of $57 \mathrm{~mm}$. The compositions of the tubes are presented in Table 1.

\subsection{Oxide Film Formation During Immersion in Natural Seawater}

The samples used for corrosion product film formation in natural seawater and electrochemical erosion-corrosion test in $\mathrm{NaCl}$ solution were rings of $1 \mathrm{~cm}$ long cut from the as-received $\Phi 57 \mathrm{~mm}$ tubes. The surfaces of the samples were polished on a modified drilling machine with a series of grit $(400,600$, and 800$)$ abrasive papers, followed by rinsing with distilled water, immersed in absolute alcohol in an ultrasonic bath for degreasing, and then dried in a stream of warm air. The prepared specimens were then immediately preserved in sealed plastic bags prior to use.

The samples were fixed in insulating plastic frames before being exposed to seawater in Zhoushan sea area $\left(30^{\circ} 00^{\prime} \mathrm{N}\right.$ latitude, and $122^{\circ} 06^{\prime} \mathrm{E}$ longitude) of China for the duration of 30,90 , and 180 days for natural seawater corrosion and oxide film formation as shown in Fig. 1. The tube samples were submerged at a depth of $5.3 \mathrm{~m}$ below 
Table 1 Chemical composition (wt\%) of the two experimental $90 \mathrm{Cu}-10 \mathrm{Ni}$ alloy tubes

\begin{tabular}{llllllllll}
\hline Material & $\mathrm{Ni}$ & $\mathrm{Fe}$ & $\mathrm{Mn}$ & $\mathrm{C}$ & $\mathrm{Pb}$ & $\mathrm{S}$ & $\mathrm{P}$ & $\mathrm{Zn}$ & $\mathrm{Cu}$ \\
\hline Tube A & 10.4 & 1.73 & 0.68 & $0.014-0.027$ & $<0.001$ & 0.004 & 0.003 & $<0.01$ & Bal. \\
Tube B & 10.4 & 1.51 & 0.59 & 0.009 & $<0.001$ & 0.002 & 0.002 & $<0.01$ & Bal. \\
\hline
\end{tabular}

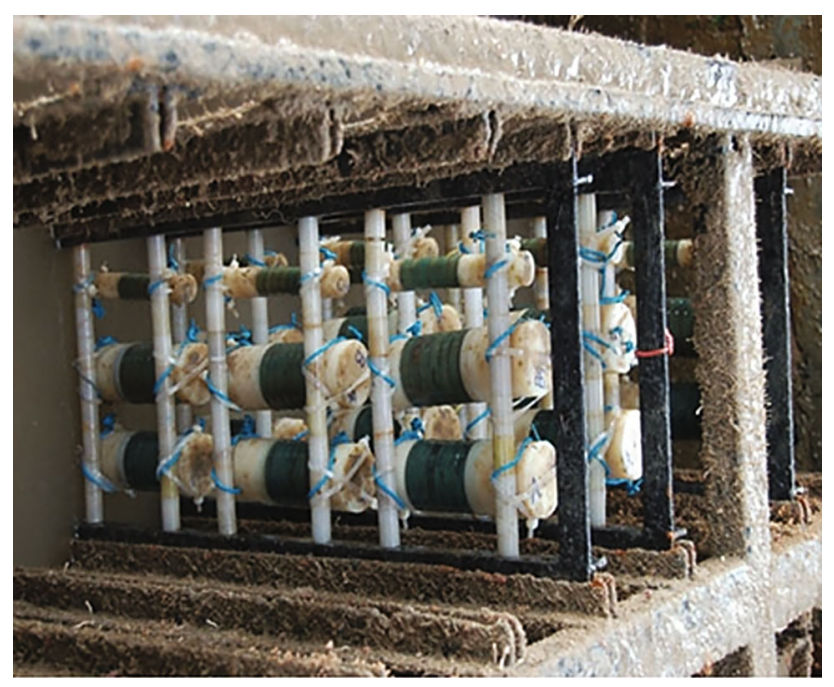

Fig. 1 Immersion test in Zhoushan sea area, China

the highest tide level and at a depth of $1.3 \mathrm{~m}$ below the lowest tide level. Average seawater temperature, salinity, conductivity, $\mathrm{pH}$, dissolved oxygen, and silt recorded within the period of immersion (between May and November) are $23.3{ }^{\circ} \mathrm{C}, 22.6 \%$, 34,623.7 $\mu \mathrm{S} / \mathrm{cm}, 8.1$, $7.1 \mathrm{mg} / \mathrm{l}$, and $707.4 \mathrm{mg} / \mathrm{l}$, respectively. At the end of each exposure period, the samples were retrieved and also removed from the plastic frame for surface analysis and electrochemical measurements.

\subsection{Electrochemical Measurements for Erosion- Corrosion}

Electrochemical measurements were carried out for the ring samples after immersion in natural seawater. Freshly polished samples with the same dimension but no corrosion product films were used as the contrast samples. A $3.5 \mathrm{wt} \%$ $\mathrm{NaCl}$ solution prepared from analytical grade $\mathrm{NaCl}$ and distilled water was used as the test medium to simulate seawater in the laboratory. The $\mathrm{pH}$ of the $\mathrm{NaCl}$ solution was 6.8. Electrochemical measurements were performed in dynamic flow conditions of the $\mathrm{NaCl}$ solution by an experimental apparatus composed of a rotating cylinder electrode (RCE) system connected to the Gamry Reference 1000 potentiostat/galvanostat/ZRA system. Each of the ring samples for electrochemical test was mounted into the cylindrical holder of the RCE made from nylon with rubber washers to prevent crevice corrosion. The sample was electrically connected by a wire through the inner wall to the terminals of the Gamry Reference 1000. The exposed surface area of the working electrode was $17.90 \mathrm{~cm}^{2}$. The experiments were performed at three different electrode rotation rates: 400,1300 , and $2200 \mathrm{rpm}$, corresponding to the linear velocities of $1.19,3.88$, and $6.56 \mathrm{~m} / \mathrm{s}$ respectively. The speed was selected based on seawater flow velocities commonly observed in the field of application [17]. Two graphite bars used as the counter electrodes were symmetrically distributed while a saturated calomel electrode (SCE) utilized as the reference electrode was connected by a salt bridge.

Before impedance and polarization experiments, the open-circuit potential of the working electrode was monitored for $1 \mathrm{~h}$ to reach a steady state. EIS measurements were conducted using AC signal potential of $10 \mathrm{mV}$ in the frequency range of $100 \mathrm{kHz}-0.01 \mathrm{~Hz}$ at open-circuit potentials. Potentiodynamic polarization curves were swept from -0.5 to $1.1 \mathrm{~V}$ (vs. OCP) at a scan rate of $0.5 \mathrm{mV} \mathrm{s}^{-1}$. All the measurements were carried out at least three times with parallel specimens to ensure good reproducibility. The measured data were analyzed using Gamry Echem Analyst (version 6.11) software.

\subsection{Characterization of the Corrosion Product Film}

\subsubsection{Cross-Sectional Morphology Observation and Composition Analysis}

The morphology observation and composition analysis on the cross section of the corrosion product film on the $90 \mathrm{Cu}-10 \mathrm{Ni}$ alloy tubes after each immersion in natural seawater were conducted by a scanning electron microscopy/energy-dispersive X-ray detector (SEM/EDS, INSPECT F50). A small piece of the sample cut from the ring samples after immersion in natural seawater was mounted with resin and then ground down to 5000-grit abrasive paper and mildly polished with $1.0 \mu \mathrm{m}$ diamond paste. The surface of the samples was sprayed with carbon in order to enhance the conductivity of the corrosion product films before being inserted into the SEM chamber.

\subsubsection{XRD Analysis}

The components of the corrosion product film after each immersion were measured by X-ray diffraction (Panalytical X'pert pro, $\mathrm{Cu} K \alpha$ radiation at $40 \mathrm{~kW}$, PA Analytical, 

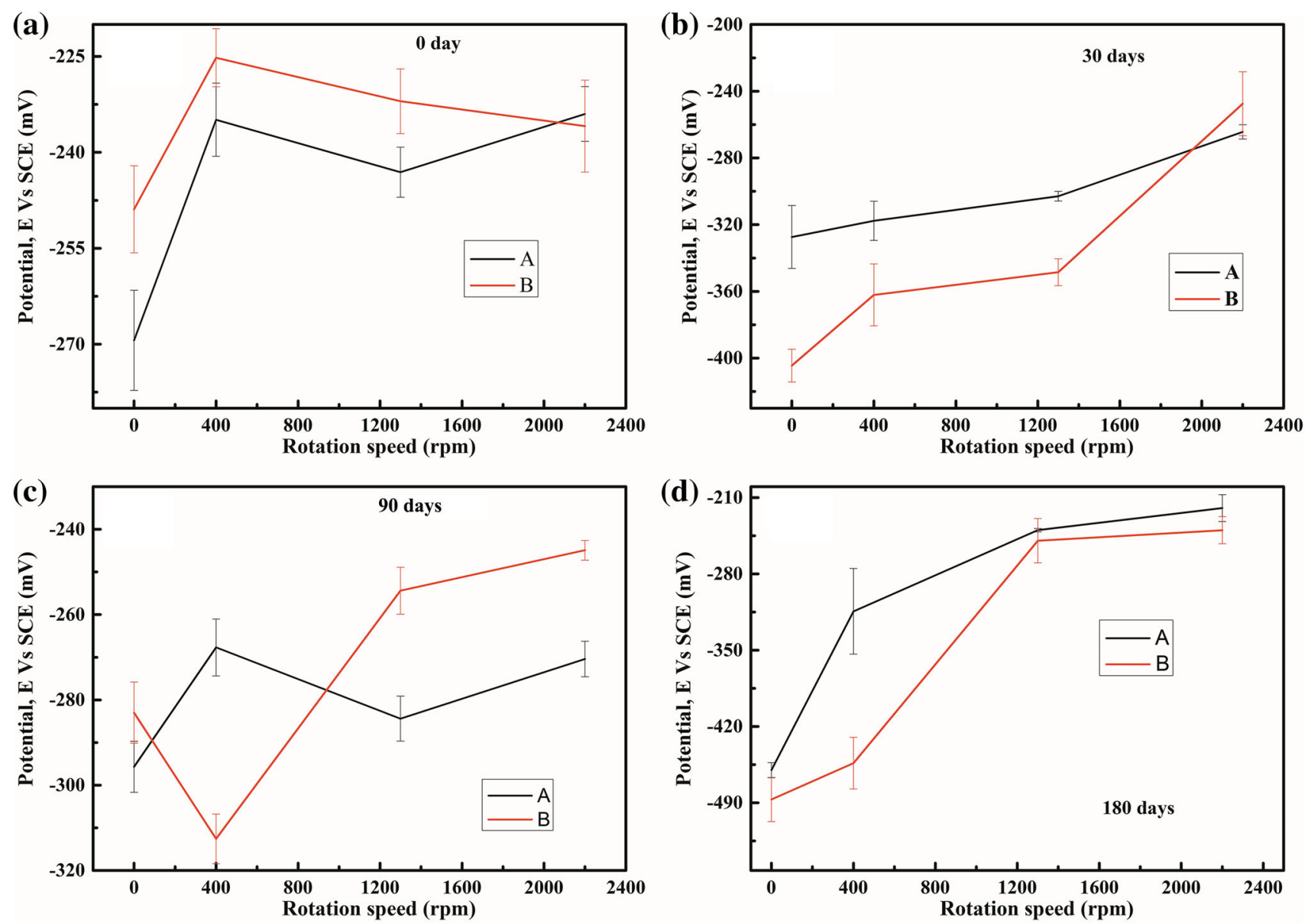

Fig. 2 OCP measurements for Tubes A and B after a 0, b 30, c 90, d 180 day's immersion in natural seawater

Almelo, Holland) with a $2.0^{\circ}$ min scanning speed and a $10-90^{\circ}$ of $2 \theta$ range. The corrosion products were scraped of the metal sample, and the powdered samples were employed for the XRD analysis.

\subsubsection{XPS Analysis}

Surface analysis of the corrosion product film using X-ray photoelectron spectroscopy (XPS) was carried out after each immersion with the aim of understanding the nature of the composition at various depths within the corrosion product film. However, collecting signals of elements at various depths within films of above $6 \mu \mathrm{m}$ in thickness became a problem because the films were too thick to be sputtered through by argon ions at affordable experimental cost. A technique of wearing and sputtering was therefore applied to resolve the problem of thickness. Specifically, pieces of $\sim 10 \mathrm{~mm} \times 10 \mathrm{~mm}$ for Samples A and B were cut manually from the ring coupon after immersion in seawater with corrosion product film intact; the corrosion product films in the selected area on the pieces were worn off slightly by a cylinder surface rolled from a fine abrasive paper till the alloy substrate was exposed. The already prepared samples were introduced into the XPS chamber, and signals from the outer layers of the film were collected at the original surface of the film after sputtering for $300 \mathrm{~s}$. The signals from the inner layer were also collected after sputtering for $300 \mathrm{~s}$ at the slope between the exposed alloy substrate and the original surface formed by the wearing process described above. The XPS measurements were carried out using a VG ESCALAB $250 \mathrm{X}$-ray photoelectron spectrometer. The photoelectrons were excited with $\mathrm{Al}$ $\mathrm{Ka}(1486.6 \mathrm{eV}) \mathrm{X}$-ray source, and the analyzer pass energy was $50.0 \mathrm{eV}$. Binding energies (BEs) were measured against the surface carbon contamination at $284.6 \mathrm{eV}$. The sputtering rate was estimated to be approximately $0.2 \mathrm{~nm} \mathrm{~s}^{-1}\left(\mathrm{vs} \mathrm{Ta}_{2} \mathrm{O}_{5}\right)$. The XPS PEAK software, based on a nonlinear least-square regression method, was used to bring about the fitting process. 

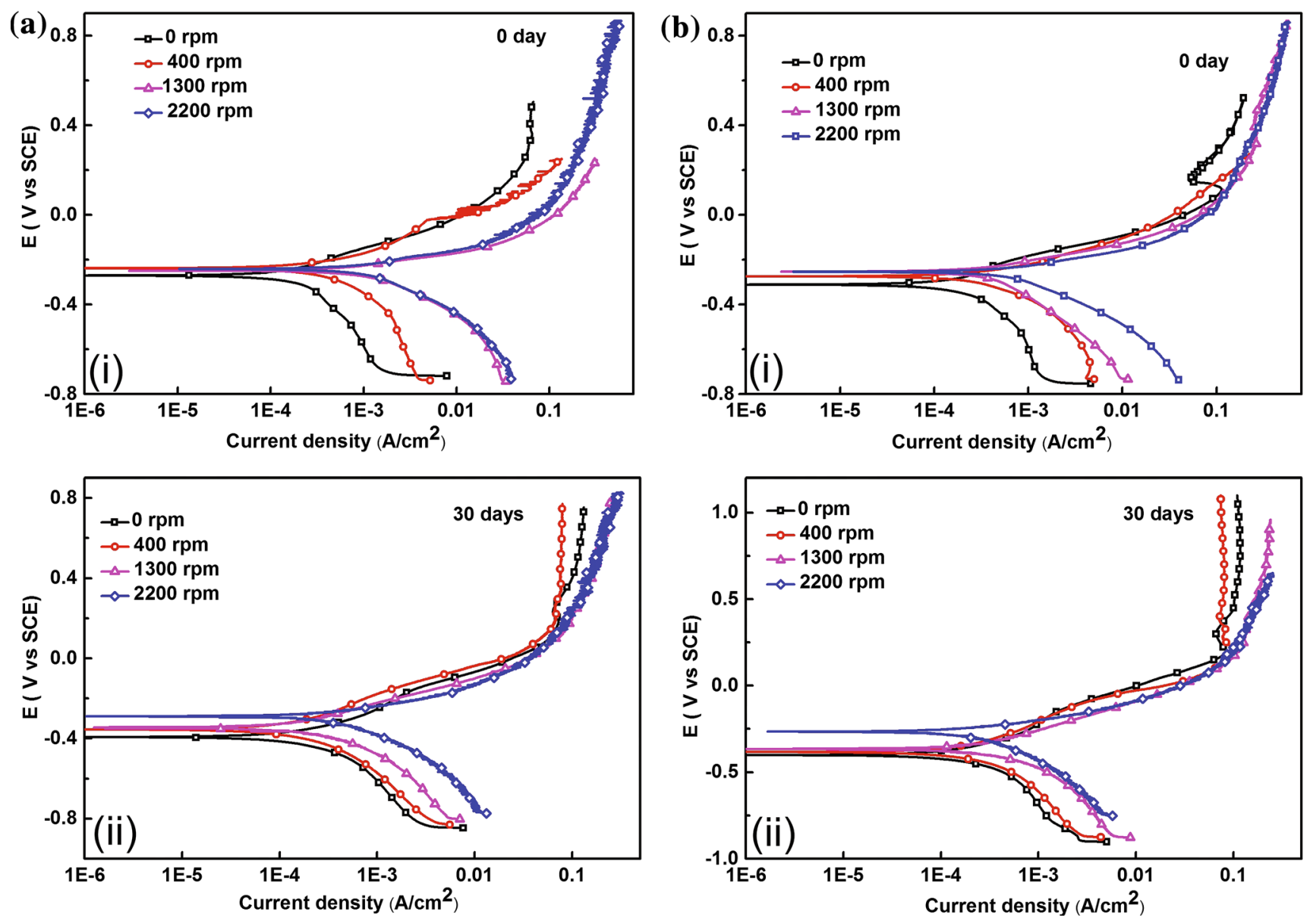

Fig. 3 Potentiodynamic polarization curves for the freshly polished ( 0 day) Tubes A a and B b, after (i) 0 and (ii) 30 days' immersion in natural seawater

\section{Results}

\subsection{Electrochemical Erosion-Corrosion Measurements}

\subsubsection{Open-Circuit Potential Measurements}

Changes in the OCP of Tube A and Tube B with the rotation speed measured in $3.5 \mathrm{wt} \% \mathrm{NaCl}$ solution for the freshly polished samples and the ones after 30, 90, and 180 days' immersion in natural seawater are shown in Fig. 2. As we can see, OCP of the freshly polished samples shifted to more positive potential at the rotation speed of $400 \mathrm{rpm}$ compared with that in the stagnant condition and then fluctuated within the range of $10 \mathrm{mV}$ with increasing rotation speed.

After 30, 90, and 180 days' immersion in natural seawater, the OCP of the two samples shifted continuously to more positive potential with increasing flow velocity.

\subsubsection{Potentiodynamic Polarization Measurements}

Potentiodynamic polarization curves of freshly polished samples and samples after 30 days' immersion in natural seawater tested in $3.5 \mathrm{wt} \% \mathrm{NaCl}$ solution are illustrated in Fig. 3, and those of samples after 90 days and 180 days' immersion in natural seawater in Fig. 4. The cathodic current densities of the two tubes gradually increased with the increasing flow velocity as the result of the accelerated transport of dissolved oxygen to the surface of the electrode.

Table 2 presents electrochemical parameters obtained by fitting the polarization curves in Figs. 3 and 4. Apart from the result for the freshly polished Sample A, a nearly unnoticeable change is observed at the anodic regions of the polarization curves of the two samples. Thus, the electrochemical parameters were obtained by fitting the cathodic regions of the curves using the Gamry Echem Analyst software. For the freshly polished samples, the corrosion current densities $I_{\text {corr }}$ of the two specimens increased with increasing rotation speed, as seen in 

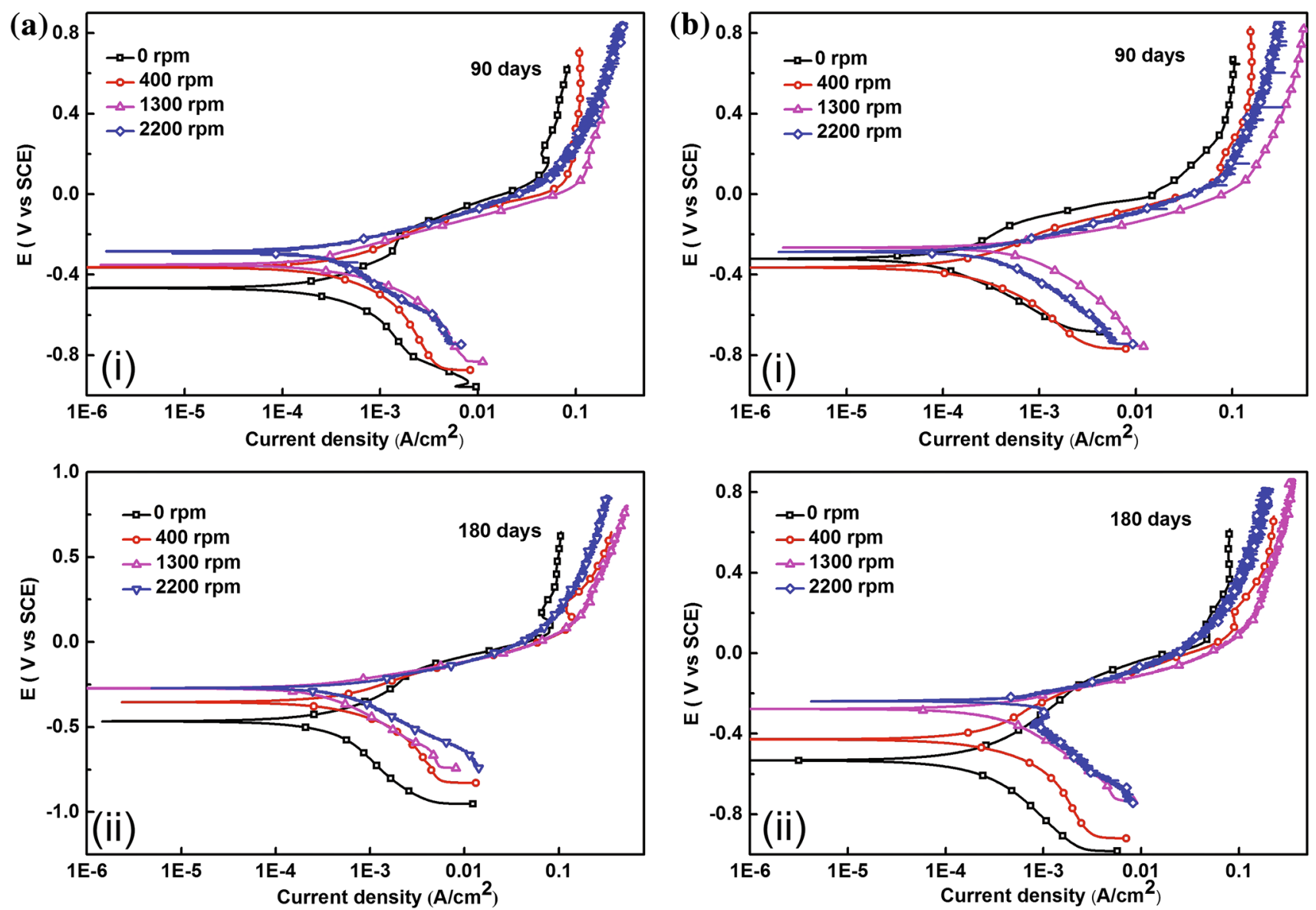

Fig. 4 Potentiodynamic polarization curves for Tubes A a and B b after (i) 90 and (ii) 180 days' immersion in natural seawater

Table 2 Corrosion parameters of samples A and B obtained from Figs. 3 and 4

\begin{tabular}{|c|c|c|c|c|c|c|c|c|c|}
\hline \multirow[t]{2}{*}{ Immersion time (day) } & \multirow[t]{2}{*}{ Rotation speed (rpm) } & \multicolumn{2}{|c|}{ Beta C (V/decade) } & \multicolumn{2}{|c|}{$E_{\text {corr }}(\mathrm{mV})$} & \multicolumn{2}{|c|}{$I_{\text {corr }}\left(\mu \mathrm{A} / \mathrm{cm}^{2}\right)$} & \multicolumn{2}{|c|}{ Corrosion rate (mpy) } \\
\hline & & A & $\mathrm{B}$ & A & $\mathrm{B}$ & A & B & A & $\mathrm{B}$ \\
\hline \multirow[t]{4}{*}{0} & 0 & 0.213 & 0.278 & -270.9 & -311.7 & 206.8 & 184.5 & 5.3 & 4.7 \\
\hline & 400 & 0.183 & 0.173 & -237.9 & -274.6 & 265.6 & 254.9 & 6.8 & 6.6 \\
\hline & 1300 & 0.175 & 0.225 & -248.8 & -253.5 & 954.1 & 323.5 & 24.5 & 8.3 \\
\hline & 2200 & 0.185 & 0.159 & -241.4 & -254.3 & 941.5 & 511.7 & 24.2 & 13.2 \\
\hline \multirow[t]{4}{*}{30} & 0 & 0.284 & 0.292 & -535.2 & -485.2 & 73.4 & 58.5 & 1.9 & 1.5 \\
\hline & 400 & 0.275 & 0.296 & -497.1 & -384.6 & 55.6 & 72.3 & 1.4 & 1.9 \\
\hline & 1300 & 0.305 & 0.274 & -373.8 & -349.4 & 31.5 & 78.9 & 0.8 & 2.9 \\
\hline & 2200 & 0.153 & 0.202 & -304.4 & -309.4 & 71.0 & 83.0 & 1.8 & 2.1 \\
\hline \multirow[t]{4}{*}{90} & 0 & 0.340 & 0.312 & -334.9 & -423.7 & 91.4 & 54.9 & 2.3 & 1.4 \\
\hline & 400 & 0.279 & 0.267 & -348.9 & -419.7 & 58.5 & 76.1 & 1.5 & 2.0 \\
\hline & 1300 & 0.269 & 0.240 & -367.2 & -362.5 & 55.7 & 136.7 & 1.4 & 3.5 \\
\hline & 2200 & 0.374 & 0.240 & -350.5 & -323.8 & 49.0 & 128.4 & 1.3 & 3.3 \\
\hline \multirow[t]{4}{*}{180} & 0 & 0.282 & 0.286 & -570.2 & -562.4 & 112.2 & 184.2 & 3.7 & 4.7 \\
\hline & 400 & 0.236 & 0.252 & -452.4 & -433.1 & 144.9 & 153.8 & 8.3 & 4.0 \\
\hline & 1300 & 0.270 & 0.242 & -322.2 & -300.5 & 159.1 & 84.3 & 4.1 & 2.2 \\
\hline & 2200 & 0.363 & 0.237 & -243.8 & -294.9 & 112.4 & 126.1 & 2.9 & 3.2 \\
\hline
\end{tabular}



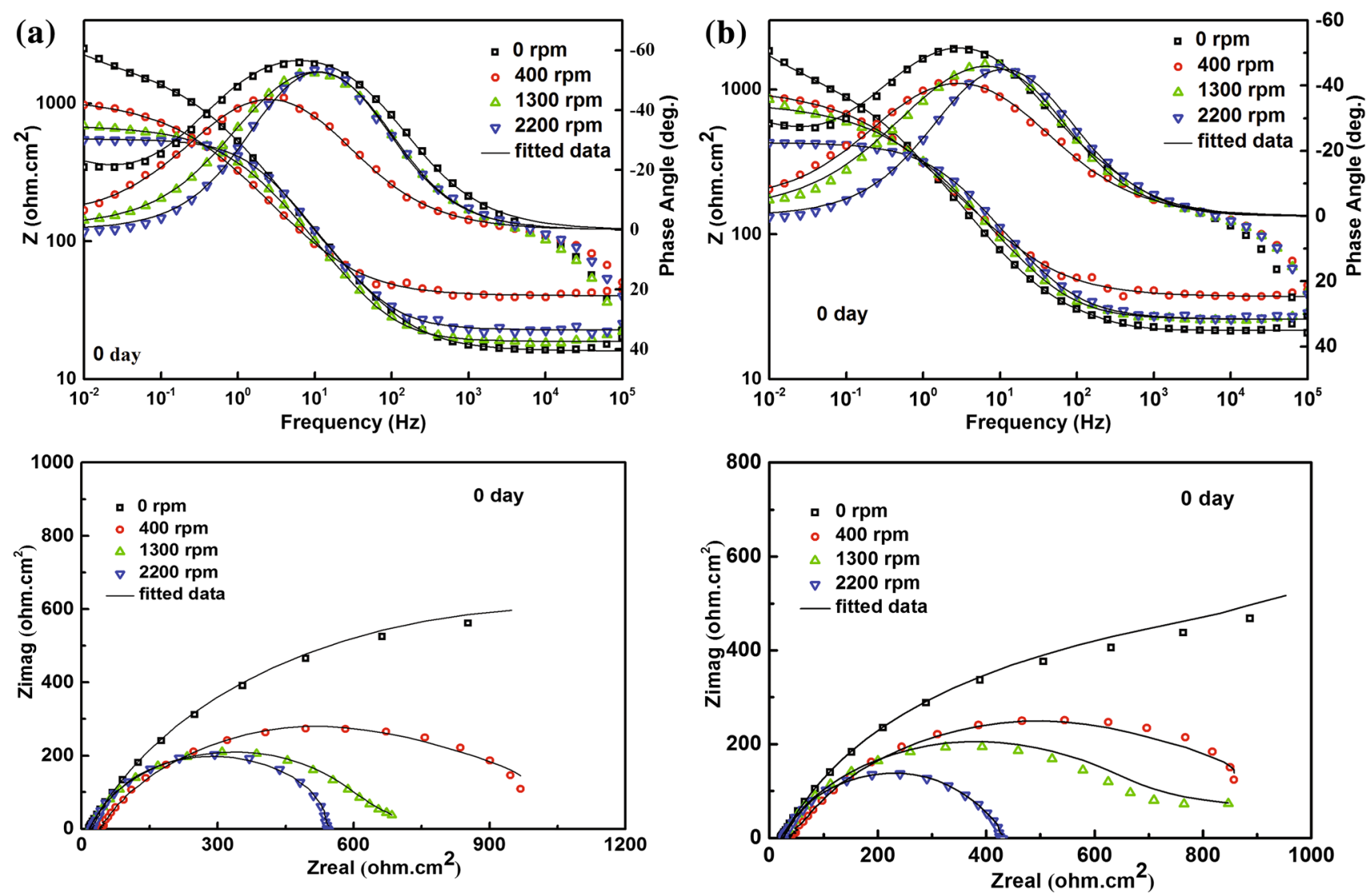

Fig. 5 Bode and Nyquist plots of freshly polished (0 day) of Tubes A a and B b

Table 2. The $I_{\text {corr }}$ values obtained for freshly polished specimens of Tube B were comparatively lower than those obtained for Tube A, especially at the rotation speeds of 1300 and $2200 \mathrm{rpm}$ where $I_{\text {corr }}$ of Tube A ascended steeply while $I_{\text {corr }}$ of Tube B increased at a much gentler rate with the increasing rotation speed.

Much lower values of $I_{\text {corr }}$ were recorded for the two samples after 30, 90, and 180 days' immersion in natural seawater in comparison with those of the freshly polished samples, which demonstrated the presence of a protective oxide film on the surface of the samples. This agrees well with the reports in the literature $[12,17,19,20]$. A decreased $I_{\text {corr }}$ of Tube A and an increased $I_{\text {corr }}$ of Tube B with increasing rotation speed were observed for samples after 30 and 90 days' immersion, as shown in Table 2. However, the $I_{\text {corr }}$ trends of the two tubes with the increasing rotation speed were reversed after 180 days' immersion, which may be due to the significant changes in the structures of their corrosion product films after 6 months immersion.

The trends of the corrosion potential $E_{\text {corr }}$ in Table 2 are in well agreement with the results of OCP.

\subsubsection{Electrochemical Impedance Spectroscopy Measurements}

EIS measurements were carried out in $3.5 \mathrm{wt} \% \mathrm{NaCl}$ solution at the stagnant condition and at three different electrode rotation speeds $(400,1300$, and $2200 \mathrm{rpm})$ for the freshly polished and the filmed samples after immersion in natural seawater. The results are presented in forms of Bode and Nyquist plots in Figs. 5, 6, 7, 8.

For the freshly polished samples, both the impedance at the low frequency end and the semicircle capacitive loop of the two specimens gradually decreased with increasing flow velocity. This indicates a decrease in the corrosion resistance of the two tubes with the increasing flow velocity, which is in agreement with the results of polarization curves.

The spectra were analyzed in terms of the equivalent electric circuits (EECs) presented in Fig. 9. Equivalent electric circuits employing constant phase elements (CPEs) are regularly used to fit impedance spectra because the associated distribution of time constants provides an improved fit [21]. Although CPEs were introduced during the fitting process, however for simplicity, the symbols $C_{\mathrm{dl}}$, $C_{\mathrm{pf}}$, and $C_{\mathrm{bf}}$ which can be defined as the capacitances of the 

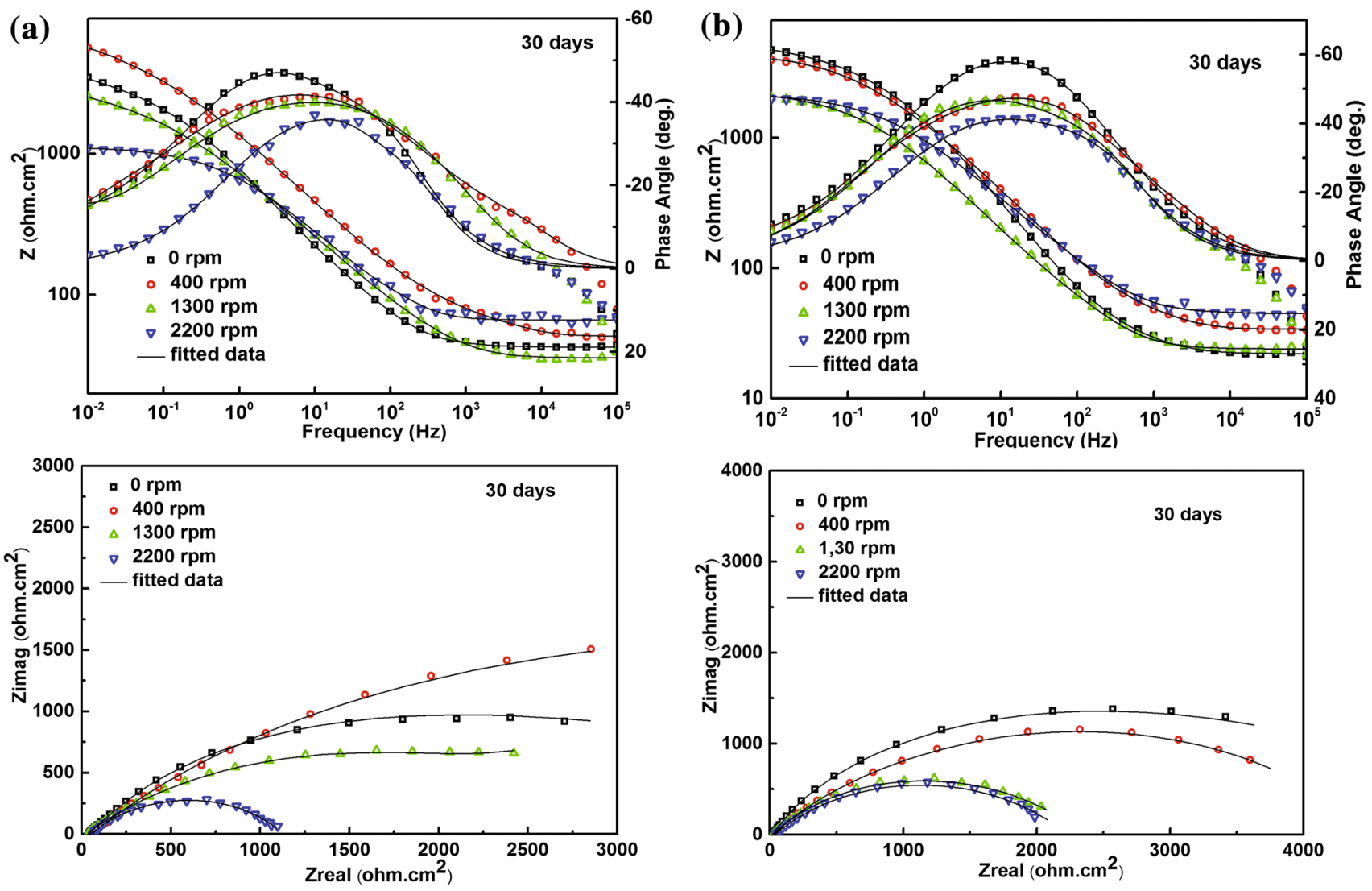

Fig. 6 Bode and Nyquist plots of Tubes A $\mathbf{a}$ and B b after 30 days' immersion in natural seawater

electric double layer, porous film, and barrier film, respectively, will be still employed. Other circuit parameters such as $R_{\mathrm{s}}, R_{\mathrm{ct}}, R_{\mathrm{pf}}, R_{\mathrm{bf}}$, and $W$ can be defined as solution resistance, charge transfer resistance, resistance of the porous film, resistance of the barrier film, and Warburg resistance, respectively. The polarization resistance, $R_{\mathrm{p}}$, was calculated to be the sum of $R_{\mathrm{ct}}, R_{\mathrm{pf}}$, and $R_{\mathrm{bf}}$. Equivalent circuit (a) was used to fit the EIS spectra of the freshly polished samples while (b) was used to fit the EIS spectra of the filmed samples. Equivalent circuit (a) models two time constants, and the resistances are given as $R_{\mathrm{ct}}$ and $R_{\mathrm{f}}$. Therefore, the $R_{\mathrm{p}}$ of the freshly polished samples is given as the sum of $R_{\mathrm{ct}}$ and $R_{\mathrm{f}}$. The fitted electrochemical parameters are presented in Tables 3 and 4 . It can be seen that much higher values of both $R_{\mathrm{pf}}$ and $R_{\mathrm{bf}}$ than $R_{\mathrm{ct}}$ were recorded for the two specimens, which gives an indication that the corrosion process was controlled by the diffusion through the oxide films, rather than the charge transfer process. Coincidently, Campbell et al. [22] concluded from the parabolic corrosion rare trend that ion diffusion through the corrosion product film played a major role in the corrosion rate of the copper-nickel alloy. The Warburg impedance of the two samples showed opposing trend, while that of Tube A increased, that of Tube B decreased with increasing flow velocity indicating a decrease in diffusion rate for Tube A and an increase in diffusion rate for Tube B.

Though equivalent circuits with two and three time constants were employed in fitting the EIS spectra, only one broad peak can be distinguished for the two tubes. It may be because that the peaks are overlapped due to the complexity of the reactions associated with the effect of flow on the electrode surface. This is evident in the spectra of the filmed samples with broader peaks than those of the freshly polished samples. The broadening of the peak angles for the filmed samples toward the high-frequency region also indicates the presence of a duplex corrosion product film.

Figure 10 presents variation of $R_{\mathrm{p}}$ with the immersion time in natural seawater and the flow velocity used by the erosion-corrosion test. It can be seen that the corrosion resistance of the two tubes was affected by both the immersion time and the flow velocity. The $R_{\mathrm{p}}$ of the freshly polished tubes was much lower than that after immersion in natural seawater and generally decreases with increasing flow velocity. It is noticeable that the $R_{\mathrm{p}}$ of the freshly polished Tube A increased at the rotation speed of $400 \mathrm{rpm}$ compared with the $R_{\mathrm{p}}$ at the stagnant condition, indicating that the growth of oxide film was prompted by the 

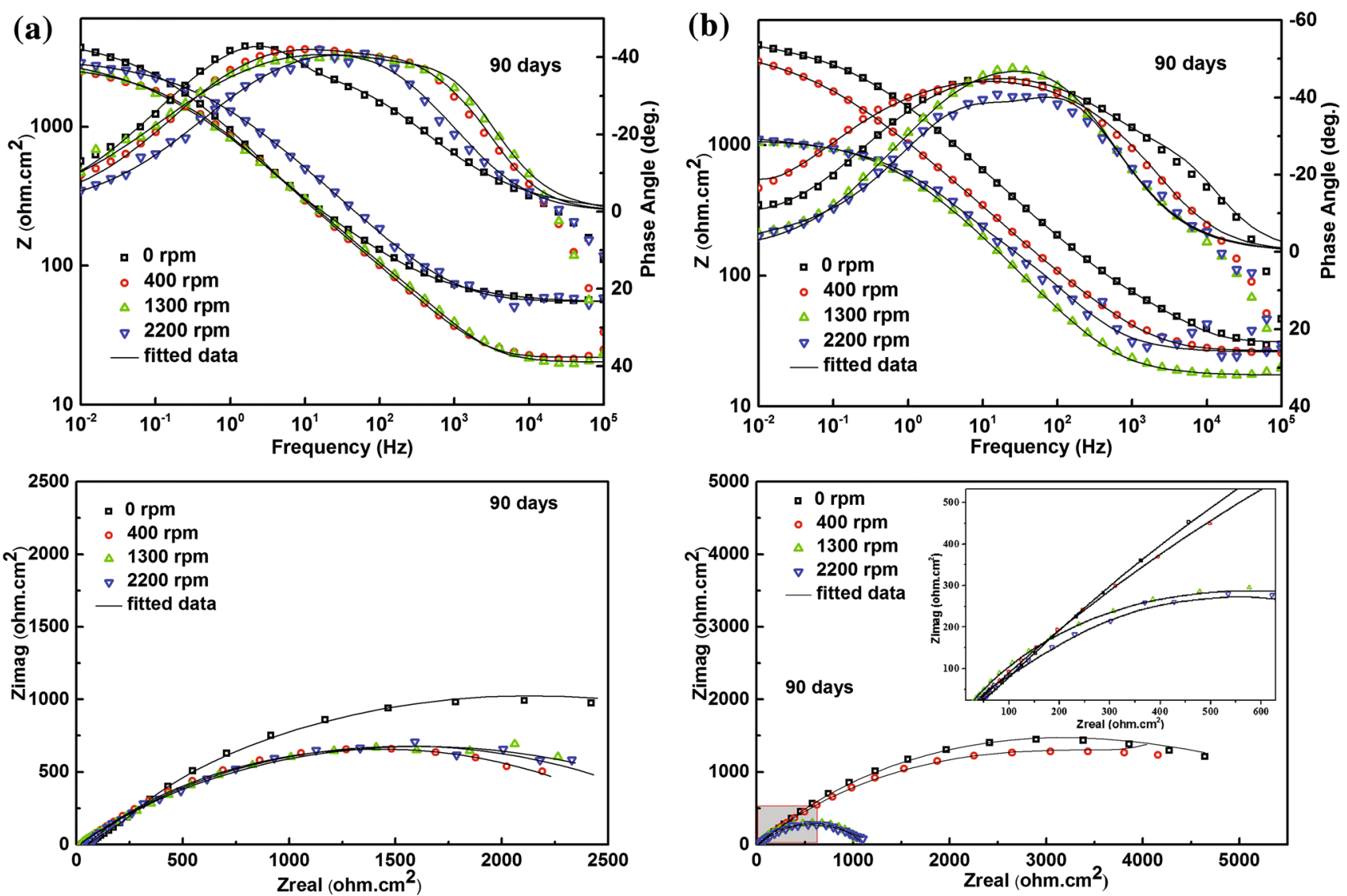

Fig. 7 Bode and Nyquist plots of Tubes A a and B b after 90 days' immersion in natural seawater

accelerated cathodic reaction due to the faster $\mathrm{O}_{2}$ transport when the flow velocity is not extremely high.

The $R_{\mathrm{p}}$ of the two tubes after 30 days' immersion in natural seawater also decreased with increasing flow velocity. But $R_{\mathrm{p}}$ of Tube $\mathrm{A}$ was higher than Tube $\mathrm{B}$ at the slower rotation speed of $400 \mathrm{rpm}$, and close to Tube B at the medium rotation speed of $1300 \mathrm{rpm}$, and much lower than Tube B at the highest rotation speed of $2200 \mathrm{rpm}$. This means that the corrosion product film of Tube A, which was more protective than that of Tube $\mathrm{B}$ at the slower flow velocity, decayed more rapidly with increasing flow velocity.

As the immersion time is increased to 90 days, the $R_{\mathrm{p}}$ of Tube $\mathrm{A}$ at the rotation speed of $400 \mathrm{rpm}$ declined compared to that at the stagnant state and then increased with increasing rotation speed from 400 to $2200 \mathrm{rpm}$, indicating that the corrosion product film was damaged partially by the hydrodynamic shear force and then got repaired by the accelerated cathodic process, thereby enhancing the film growth as a result of the further increase in flow velocity. In contrast, Tube $\mathrm{B}$ displayed the outstanding $R_{\mathrm{p}}$ at the stagnant condition and at the rotation rate of $400 \mathrm{rpm}$, which diminished dramatically as the flow velocity is increased, suggesting that the resistance to high flow velocity of the oxide film on Tube B after 90 days' immersion was rather weak.

As the immersion time is increased to 180 days, the $R_{\mathrm{p}}$ trend of Tube B with the flow velocity remained similar to that after 90 days' immersion while the $R_{\mathrm{p}}$ of Tube A declined monotonically with the flow velocity, which indicates that the film on Tube A after 180 days' immersion deteriorates continuously with the increasing rotation speed. The $R_{\mathrm{p}}$ values of Tube $\mathrm{B}$ at the stagnant condition and at the rotation speed of $400 \mathrm{rpm}$ were less than half of their counterparts after 90 days' immersion, indicating that the protectiveness of the corrosion product film on Tube B deteriorated seriously after 180 days' immersion. In contrast, the $R_{\mathrm{p}}$ values of Tube B at the rotation speeds of 1300 and $2200 \mathrm{rpm}$ were close to their counterparts after 90 days' immersion, suggesting identical behavior for the corrosion product film formed after 180' or 90 days' immersion at higher rotation speeds.

\subsection{SEM/EDS Analysis of the Corrosion Product Film}

Figure 11 shows the cross-sectional morphologies (backscattered electron images) of the corrosion product 

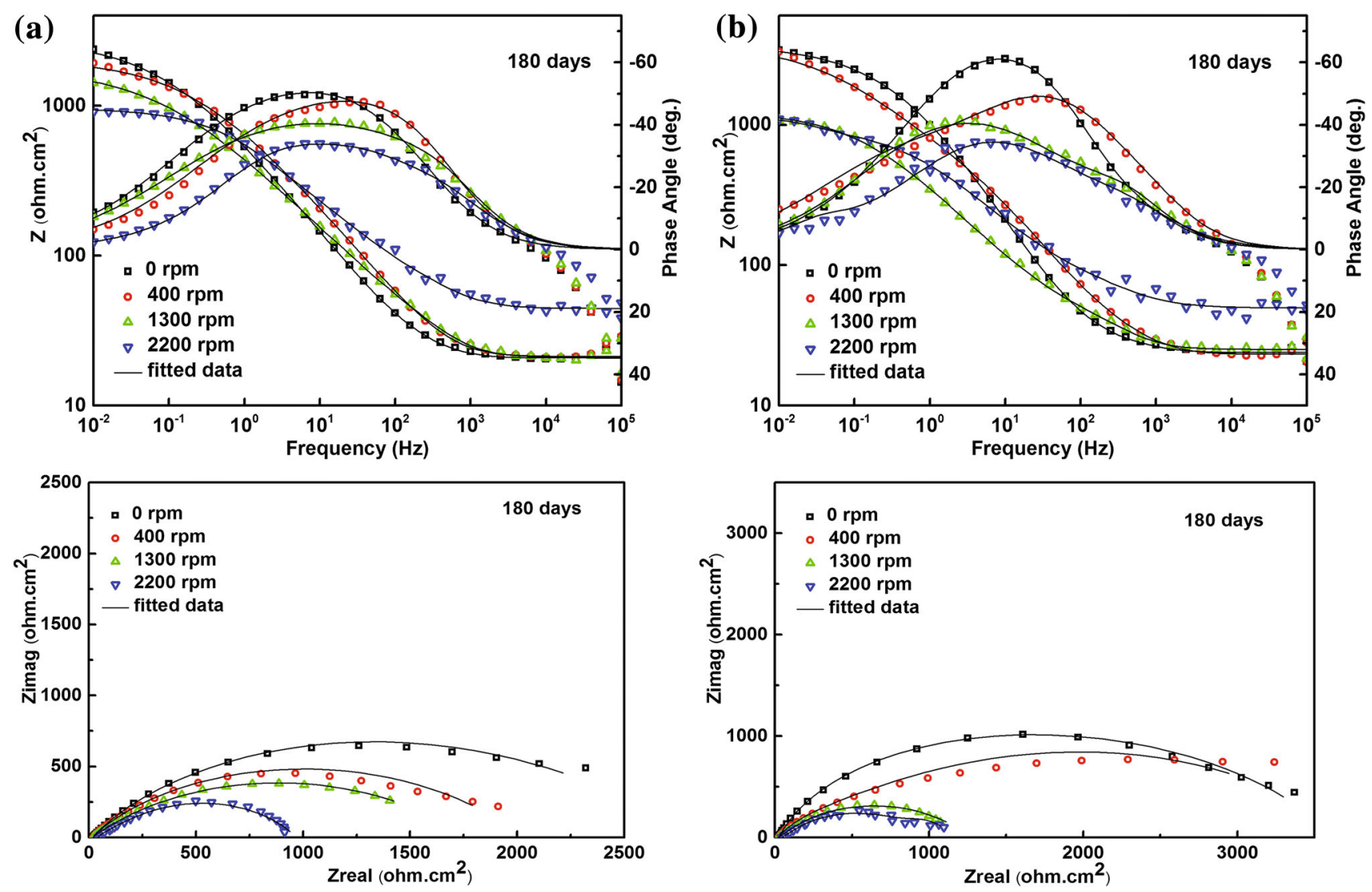

Fig. 8 Bode and Nyquist plots of Tubes A a and B b after 180 days' immersion in natural seawater

(a)

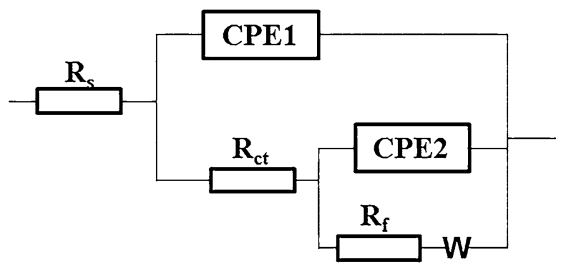

(b)

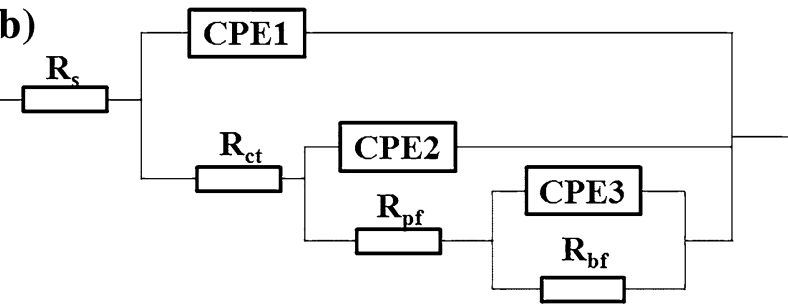

Fig. 9 Equivalent circuits used for fitting the impedance spectra of the three alloy specimens after $0,30,90$, and 180 days' immersion in natural seawater. Equivalent circuit a for freshly polished samples ( 0 day) and equivalent circuit $\mathbf{b}$ for the filmed samples after 30,90 , and 180 days' immersion in natural seawater

films formed on Tubes A (a, c, e) and B (b, d, f) after 30, 90, and 180 days' exposure time in natural seawater. The corresponding EDS line scan analyses were displayed in Fig. 12.
The films on both of the two tubes after 30 days' immersion in natural seawater consisted of three layers: a loose outer layer, a compact middle layer, and a thin and white inner layer. There existed a gap between the inner layer and the alloy substrate for the film on Tube A, between the middle and the inner layer for Tube B. As can be seen from Fig. 12a, the Ni content within the outer layer of the film on Tube A after 30 days' immersion was quite low and increased to a relatively stable level at the inner layer and the bottom part of the middle layer, but never exceeded the Ni content in the alloy substrate. The trace of $\mathrm{Fe}$ also increased from the outer layer, formed a flat peak within the middle and the inner layers, and then decreased when approaching the alloy substrate. A small peak of the chloride content appeared in the outer layer, and a bigger peak occurred in the middle layer. As for Tube $\mathrm{B}$, the $\mathrm{Cu}$ content increased from the outer layer to the inner layer, there was hardly any trace of $\mathrm{Ni}$ detected in the outer layer, and a relatively stable content of $\mathrm{Ni}$ could be detected within the middle layer, which then declined in the inner layer. Anyway, the Ni content within the corrosion product film was lower than the level in the alloy substrate, while the $\mathrm{Fe}$ content within the film was no less than that in the alloy substrate. Another noticeable feature is that the inner 
Table 3 Circuit parameters for sample A after 0, 30, 90, and 180 days' immersion in natural seawater

\begin{tabular}{|c|c|c|c|c|c|c|c|c|c|c|c|c|c|}
\hline $\begin{array}{l}\text { Immersion } \\
\text { time (day) }\end{array}$ & $\begin{array}{l}\text { Rotating } \\
\text { speed (rpm) }\end{array}$ & $\begin{array}{l}R_{\mathrm{s}}(\Omega \\
\left.\mathrm{cm}^{2}\right)\end{array}$ & $\begin{array}{l}R_{\mathrm{ct}}(\mathrm{k} \Omega \\
\left.\mathrm{cm}^{2}\right)\end{array}$ & $\begin{array}{l}C_{\mathrm{dl}}(\mu \mathrm{F} \\
\left.\mathrm{cm}^{-2}\right)\end{array}$ & $n_{1}$ & $\begin{array}{l}R_{\mathrm{fp}}(\mathrm{k} \Omega \\
\left.\mathrm{cm}^{2}\right)\end{array}$ & $\begin{array}{l}C_{\mathrm{fp}}(\mu \mathrm{F} \\
\left.\mathrm{cm}^{-2}\right)\end{array}$ & $n_{2}$ & $\begin{array}{l}W\left(\Omega^{-1}\right. \\
\left.\mathrm{S}^{-1 / 2}\right)\end{array}$ & $\begin{array}{l}R_{\mathrm{fb}}(\mathrm{k} \Omega \\
\left.\mathrm{cm}^{2}\right)\end{array}$ & $\begin{array}{l}C_{\mathrm{fb}}(\mu \mathrm{F} \\
\left.\mathrm{cm}^{-2}\right)\end{array}$ & $n_{3}$ & $\begin{array}{l}R_{\mathrm{p}}(\mathrm{k} \Omega \\
\left.\mathrm{cm}^{2}\right)\end{array}$ \\
\hline \multirow[t]{4}{*}{0} & 0 & 16 & 0.389 & 42.1 & 0.74 & 1.16 & 0.03 & 0.98 & 0.004 & & & & 1.55 \\
\hline & 400 & 40.3 & 0.904 & 78.1 & 0.7 & 0.06 & 2730 & 1 & 0.055 & & & & 0.96 \\
\hline & 1300 & 18.8 & 0.008 & 22.1 & 0.86 & 0.67 & 30.2 & 0.53 & 0.371 & & & & 0.68 \\
\hline & 2200 & 22.7 & 0.531 & 280.9 & 0.82 & 0.01 & 82.3 & 0.02 & 0.915 & & & & 0.54 \\
\hline \multirow[t]{4}{*}{30} & 0 & 42.6 & 0.177 & 9.6 & 0.82 & 0.47 & 18.97 & 0.7 & & 6.16 & 36.71 & 0.25 & 6.81 \\
\hline & 400 & 50.9 & 0.016 & 0.13 & 1 & 5.87 & 23.62 & 0.55 & & 2.21 & 210.4 & 0.64 & 8.09 \\
\hline & 1300 & 35.9 & 0.015 & 0.9 & 0.97 & 2.99 & 45.84 & 0.51 & & 1.11 & 2850 & 0.88 & 4.11 \\
\hline & 2200 & 66.4 & 0.095 & 2.41 & 0.95 & 0.16 & 4.95 & 0.92 & & 0.81 & 45.3 & 0.58 & 1.06 \\
\hline \multirow[t]{4}{*}{90} & 0 & 54.3 & 1.051 & 31.23 & 0.55 & 1.45 & 2.83 & 0.99 & & 1.78 & 0.02 & 0.84 & 4.28 \\
\hline & 400 & 22 & 0.027 & 0.51 & 1 & 0.08 & 3.95 & 0.79 & & 2.72 & 32.81 & 0.54 & 2.82 \\
\hline & 1300 & 20.2 & 0.01 & 1 & 0.91 & 0.05 & 12.22 & 0.41 & & 3.22 & 27.66 & 0.54 & 3.28 \\
\hline & 2200 & 55.4 & 0.023 & 0.62 & 0.93 & 3.02 & 20.31 & 0.52 & & 2.8 & 0.19 & 0.78 & 5.84 \\
\hline \multirow[t]{4}{*}{180} & 0 & 20.8 & 0.011 & 2.89 & 1 & 2.13 & 51.28 & 0.6 & & 0.87 & 165.7 & 0.22 & 3.01 \\
\hline & 400 & 21.3 & 0.016 & 1.93 & 0.99 & 1.98 & 42.81 & 0.55 & & 0.01 & 875.7 & 0.89 & 2.01 \\
\hline & 1300 & 21 & 0.018 & 2.11 & 0.97 & 0.87 & 74.26 & 0.52 & & 0.85 & 3.07 & 0.37 & 1.74 \\
\hline & 2200 & 44.4 & 0.04 & 2.03 & 0.9 & 0.45 & 31.58 & 0.6 & & 0.44 & 24.61 & 0.74 & 0.93 \\
\hline
\end{tabular}

Table 4 Circuit parameters for sample B after 0, 30, 90, and 180 days' immersion in natural seawater

\begin{tabular}{|c|c|c|c|c|c|c|c|c|c|c|c|c|c|}
\hline $\begin{array}{l}\text { Immersion } \\
\text { time (day) }\end{array}$ & $\begin{array}{l}\text { Rotating } \\
\text { speed (rpm) }\end{array}$ & $\begin{array}{l}R_{\mathrm{s}}(\Omega \\
\left.\mathrm{cm}^{2}\right)\end{array}$ & $\begin{array}{l}R_{\mathrm{ct}}(\mathrm{k} \Omega \\
\left.\mathrm{cm}^{2}\right)\end{array}$ & $\begin{array}{l}C_{\mathrm{dl}}(\mu \mathrm{F} \\
\left.\mathrm{cm}^{-2}\right)\end{array}$ & $n_{1}$ & $\begin{array}{l}R_{\mathrm{fp}}(\mathrm{k} \Omega \\
\left.\mathrm{cm}^{2}\right)\end{array}$ & $\begin{array}{l}C_{\mathrm{fp}}(\mu \mathrm{F} \\
\left.\mathrm{cm}^{-2}\right)\end{array}$ & $n_{2}$ & $\begin{array}{l}W\left(\Omega^{-1}\right. \\
\left.\mathrm{S}^{-1 / 2}\right)\end{array}$ & $\begin{array}{l}R_{\mathrm{fb}}(\mathrm{k} \Omega \\
\left.\mathrm{cm}^{2}\right)\end{array}$ & $\begin{array}{l}C_{\mathrm{fb}}(\mu \mathrm{F} \\
\left.\mathrm{cm}^{-2}\right)\end{array}$ & $n_{3}$ & $\begin{array}{l}R_{\mathrm{p}}(\mathrm{k} \Omega \\
\left.\mathrm{cm}^{2}\right)\end{array}$ \\
\hline \multirow[t]{4}{*}{0} & 0 & 21.8 & 0.011 & 6.42 & 1 & 1.961 & 70.55 & 0.69 & 0.004 & & & & 1.97 \\
\hline & 400 & 37.2 & 0.838 & 85.84 & 0.65 & 1 & 2004 & 0.31 & 0.88 & & & & 1.84 \\
\hline & 1300 & 25.9 & 0.35 & 31.33 & 0.81 & 0.796 & 53.99 & 0.45 & 0.462 & & & & 1.15 \\
\hline & 2200 & 26 & 0.401 & 39.49 & 0.76 & 0.137 & 2620 & 0.4 & 0.447 & & & & 0.54 \\
\hline \multirow[t]{4}{*}{30} & 0 & 21.9 & 0.031 & 3.62 & 0.86 & 2.035 & 10.45 & 0.7 & & 4.212 & 29.59 & 0.34 & 6.28 \\
\hline & 400 & 34 & 0.015 & 3.71 & 1 & 2.678 & 18.12 & 0.61 & & 1.793 & 26.44 & 0.6 & 4.49 \\
\hline & 1300 & 23.9 & 0.053 & 5.59 & 0.86 & 1.261 & 37.28 & 0.58 & & 2.478 & 62.83 & 0.01 & 3.79 \\
\hline & 2200 & 44.7 & 0.128 & 4.55 & 0.8 & 1.896 & 24.23 & 0.55 & & 0.164 & 170.7 & 0.12 & 2.19 \\
\hline \multirow[t]{4}{*}{90} & 0 & 31.2 & 0.024 & 10.51 & 1 & 6.023 & 14.11 & 0.57 & & 3.541 & 943 & 0.66 & 9.59 \\
\hline & 400 & 26.7 & 0.025 & 1.2 & 0.9 & 4.703 & 31.67 & 0.52 & & 4.75 & 2195 & 1 & 9.48 \\
\hline & 1300 & 17.3 & 0.192 & 16.18 & 0.74 & 0.829 & 29.71 & 0.55 & & 0.069 & 487.2 & 0.98 & 1.09 \\
\hline & 2200 & 26 & 0.216 & 9.07 & 0.77 & 0.001 & 12.69 & 0.83 & & 1.057 & 49.47 & 0.3 & 1.27 \\
\hline \multirow[t]{4}{*}{180} & 0 & 23.9 & 0.011 & 2.05 & 1 & 2.373 & 17.1 & 0.75 & & 1.22 & 108.8 & 0.59 & 3.6 \\
\hline & 400 & 23.2 & 0.018 & 1.06 & 1 & 0.782 & 18.1 & 0.66 & & 2.948 & 47.44 & 0.53 & 3.75 \\
\hline & 1300 & 25.1 & 0.005 & 2.91 & 0.95 & 0.017 & 268.7 & 0.39 & & 1.213 & 83.67 & 0.59 & 1.23 \\
\hline & 2200 & 49.7 & 0.042 & 3.61 & 0.85 & 0.891 & 43.94 & 0.59 & & 0.173 & 2788 & 1 & 1.11 \\
\hline
\end{tabular}

layer which was enriched with $\mathrm{Cu}$ was obviously enriched with $\mathrm{O}$ and depleted of $\mathrm{Ni}$ compared with the alloy substrate.

After being immersed for 90 days, the light gray outer layer of the film on Tube A became much thicker and also looser while the dark gray middle layer was still compact.
An apparent crack occurred within the inner layer, which was probably caused by the polishing process in sample preparation although it was operated gently. But there still existed a compact inner layer which bonded firmly with the alloy substrate. From the EDS line scan analysis in Fig. 12c, the $\mathrm{Cu}$ content in the middle layer is lower than 


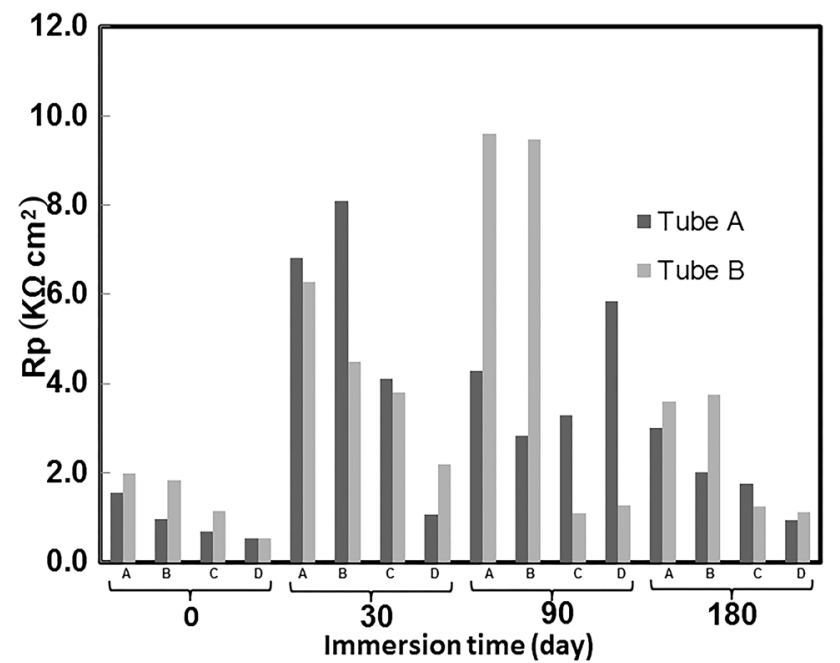

Fig. 10 Variation of $R_{\mathrm{p}}$ obtained from the EIS fitting with the immersion time in natural seawater and with increasing rotation speeds [0 rpm (A), $400 \mathrm{rpm}$ (B), $1300 \mathrm{rpm}$ (C), $2200 \mathrm{rpm}$ (D)] used in the erosion-corrosion test

that in the outer and the inner layers. The content of Fe was close to zero in the outer layer, and then increased and maintained at a relatively stable level throughout the middle and the inner layers, and finally declined when reaching the alloy substrate. The content of $\mathrm{Ni}$ increased from $\sim 0$ in the outer layer, and reached a plateau at the middle layer, and continued to rise, and finally peaked at the deep inner layer adjacent to the alloy substrate. There was no crack between the inner layer and the alloy substrate. The dark gray outer layer and the light gray middle layer on Tube B were both homogeneous and continuous, as shown in Fig. 11d. However, the bright-white inner layer on Tube B was very porous and hollow, separated by a gap from the alloy substrate, indicating a weak binding force with the substrate even though the gap was produced by polishing. The content of $\mathrm{Ni}$ was low in the outer layer, and increased to maximum in the middle layer, and then declined to $\sim 0$ in the inner layer, and finally increased when approaching the alloy substrate. Enrichment of $\mathrm{Fe}$ was observed in the outer and middle layers. The inner layer was depleted of $\mathrm{Ni}$ but not of $\mathrm{Fe}$. As with the film on Tube B after 90 days' immersion, the inner layer of the film on Tube B after 180 days' immersion was also enriched with $\mathrm{Cu}$ and $\mathrm{O}$, and depleted of $\mathrm{Ni}$.

After 180 days' immersion, the film on Tube A consisted of five layers, the most distinctive feature of which was the huge bright-white bulk in the middle that was enriched with $\mathrm{Cu}$ and $\mathrm{O}$ but depleted of $\mathrm{Ni}$ and $\mathrm{Fe}$ when compared with the alloy substrate. Based on the high content of carbon and low levels of $\mathrm{Cu}, \mathrm{Ni}$, and $\mathrm{Fe}$, the black layer on the left side of the bright-white bulk was probably the gap existing between the layers which were filled with resin during the SEM sample preparation. The inner layer was similar to the outer layer in both structure and composition, and there existed a huge crack between the inner layer and the alloy substrate. When the immersion time was increased to 180 days, the film on Tube B became of a complex sandwich structure with several disconnected layers stacked together. The EDS result showed that there existed $\mathrm{SiO}_{2}$ particles in the gap between the inner layer and the alloy substrate, which was probably from the grinding process during the sample preparation. The $\mathrm{Cu}$ content increased from the outer layer to the inner layer in stepwise way. The Ni content was higher in the second layer than in the other layers. The Fe content in the first three layers was higher than in the fourth layer and in the substrate. Bad resistance to erosion-corrosion was expected for the films after 180 days' immersion, which was verified by both the polarization curve (Table 2) and EIS (Fig. 10) results.

\subsection{XRD Analysis}

Figure 13 presents XRD patterns for the corrosion products scraped from the surface of the samples exposed in seawater for 30, 90, and 180 days, respectively. The mineral compositions of corrosion product films on the two samples were seemingly similar and did not change with the immersion time, as some characteristic peaks are marked to indicate the existence of $\mathrm{Cu}_{2} \mathrm{O}, \mathrm{Cu}_{2}(\mathrm{OH})_{3} \mathrm{Cl}$, and $\mathrm{Cu}$ in the corrosion product films. None of $\mathrm{CuO}, \mathrm{Cu}(\mathrm{OH})_{2}, \mathrm{CuCl}_{2}$ or $\mathrm{CuCl}$ and $\mathrm{Ni}$ or $\mathrm{Fe}$ compound is detected in the corrosion products of any of the samples.

The existence of $\mathrm{Cu}_{2} \mathrm{O}$ in the corrosion product film formed on $\mathrm{Cu}-\mathrm{Ni}$ alloys has been reported by several authors $[12,23,24]$, and it is known to be the major protective component in the corrosion product. The mineral $\mathrm{Cu}_{2}(\mathrm{OH})_{3} \mathrm{Cl}$ also known as atacamite detected in the corrosion product can be seen as the complex product formed from the reaction of $\mathrm{Cu}_{2} \mathrm{O}$ with water and $\mathrm{Cl}^{-}$, and its existence in the corrosion product of $\mathrm{Cu}-\mathrm{Ni}$ alloys has been widely reported $[12,25,26]$. Cu peaks in the XRD pattern may be assumed to come from the white portion in the middle and inner layers of the corrosion products film displayed by SEM result in Fig. 11.

\subsection{X-ray Photoelectron Spectroscopy Analysis}

To further understand the composition of surface film formed on the surfaces of the two $90 \mathrm{Cu}-10 \mathrm{Ni}$ alloy tubes, a detailed XPS study was undertaken. Figure 14 presents XPS depth profiles of the outer (i) and the inner (ii) layers of the corrosion product film formed on the two samples after 30 days' immersion in natural seawater. There existed none or trace of $\mathrm{Ni}$ in the outer layer of the film after 

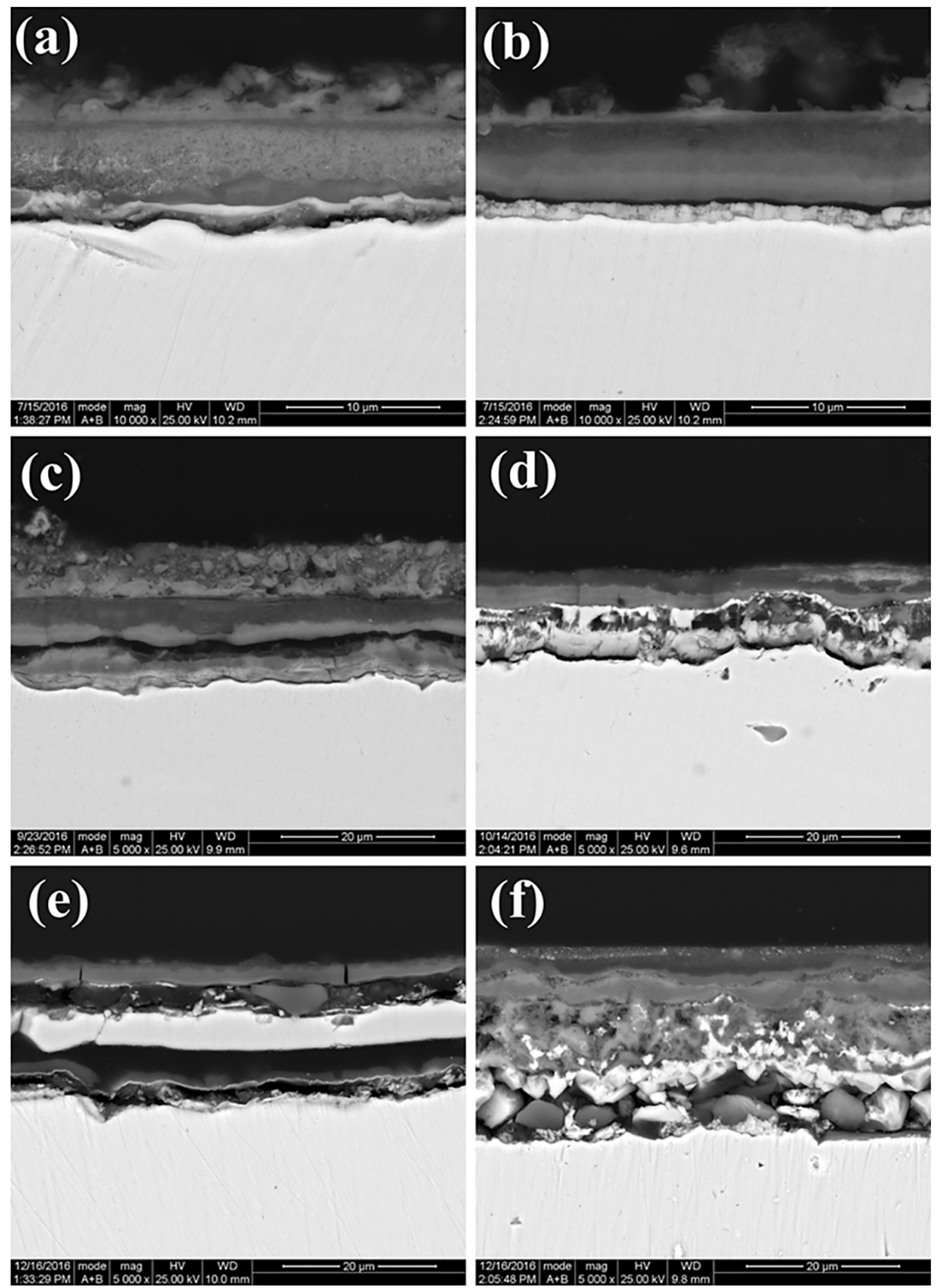

Fig. 11 Cross-sectional morphologies (backscattered electron images) of the corrosion product films formed on Tubes A a, $\mathbf{c}, \mathbf{e}$ and B b, $\mathbf{d}, \mathbf{f}$ after 30 days $\mathbf{a}, \mathbf{b}, 90$ days $\mathbf{c}, \mathbf{d}, 180$ days' e, $\mathbf{f}$ immersion in natural seawater

30 days immersion, which is basically aligned with the EDS result. The trace of Fe was invisible in both the outer and the inner layers of Tube A and Tube B probably due to the low absolute content of $\mathrm{Fe}$ in the alloy substrate. 

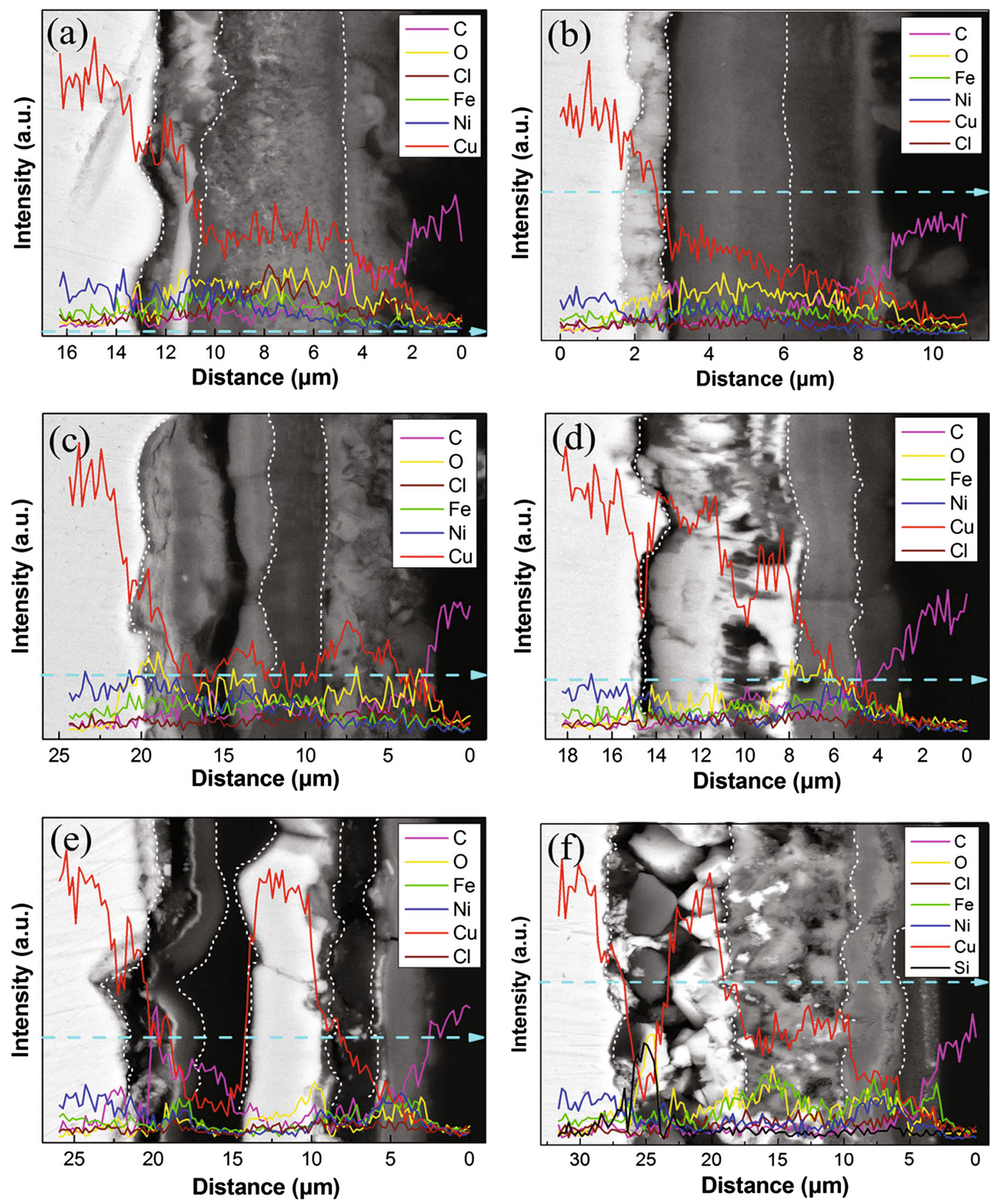

Fig. 12 EDS line scan analysis of the corrosion product films formed Tube A a, $\mathbf{a}, \mathbf{e}$ and Tube B b, d, f after 30 days $\mathbf{a}, \mathbf{b}, 90$ days $\mathbf{c}, \mathbf{d}, 180$ days' e, f immersion in natural seawater. The light blue dash line marked within each subfigure is where the EDS line scan was carried out

However, the feature of $\mathrm{Ni}$ enrichment in the inner layer on the two specimens in the order of Tube A $>$ Tube B was observed, which was in agreement with the EDS line scan analysis in Fig. 12.

When the immersion time was increased to 90 days, as shown in Fig. 15, the outer layer of the corrosion product on Tube $\mathrm{B}$ became enriched with $\mathrm{Ni}$ compared with the result after 30 days' immersion while extreme enrichment of $\mathrm{Ni}$ in the inner layer of the corrosion product on Tube A was detected.

Figure 16 presents the XPS depth profiles of the outer (i) and the inner (ii) layers of the corrosion product film formed on the two tubes after 180 days' immersion in 

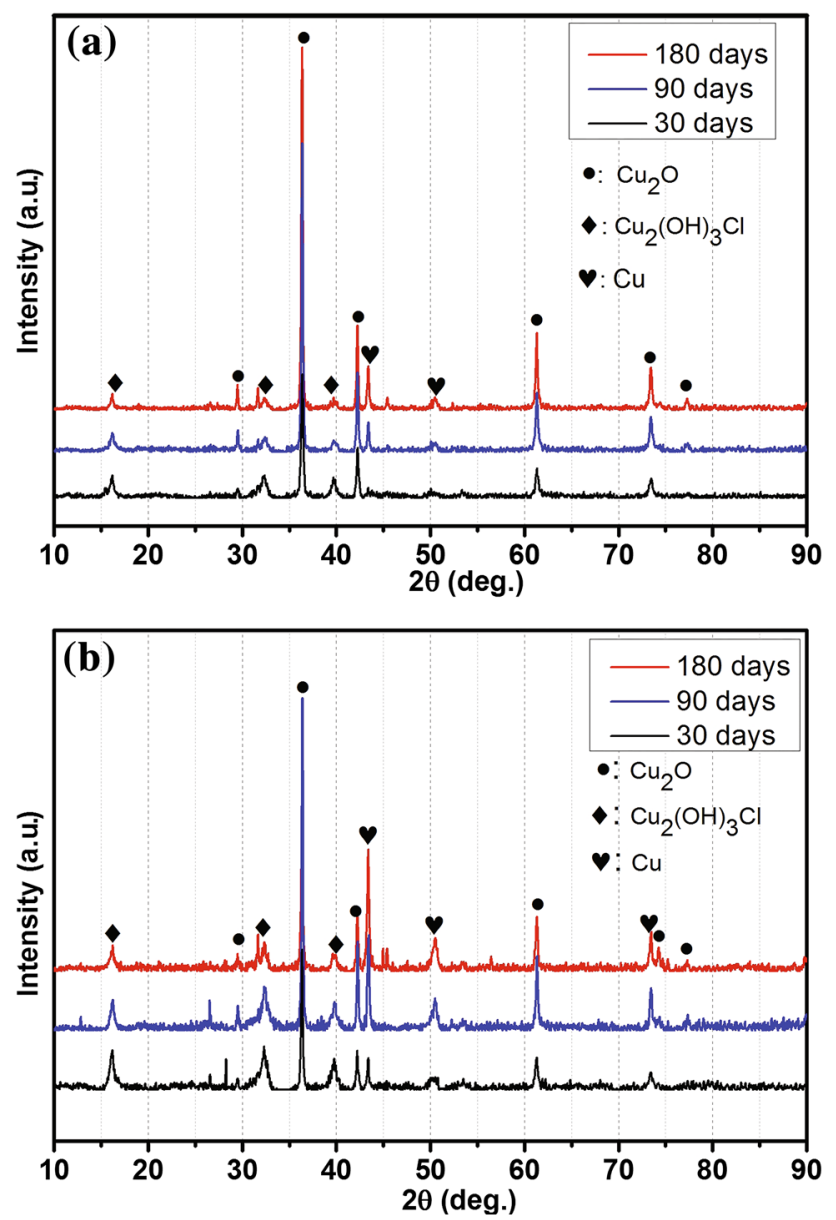

Fig. 13 XRD patterns of the corrosion product formed on the surface of the $90 \mathrm{Cu}-10 \mathrm{Ni}$ Tubes A a and B b, respectively, after 30, 90, and 180 days' immersion in natural seawater

natural seawater. It can be seen that the outer layer of Tube $\mathrm{B}$ was richer in $\mathrm{Ni}$ than the outer layer of Tube A.

The Ni spectra after being sputtered for $300 \mathrm{~s}$ corresponding to (i) the original surface of the corrosion product and (ii) the slope between the exposed alloy substrate and the original surface on the two tubes after 30,90 , and 180 days' immersion in natural seawater are presented in Figs. 17, 18, 19, respectively. The weak Ni lines from the original surface of the corrosion product make deconvolution unreliable, except for the Ni $2 p$ spectrum from the original surface of the outer layer on Tube B after 90 days' immersion. However, the spectra from the inner layer of the corrosion product give more intense peaks which make the fitting or deconvolution reliable. While fitting the $\mathrm{Ni}$ spectra, the double nature of $\mathrm{Ni} 2 p$ lines was taken into consideration and the lines were fitted with peak pairs with similar intensity ratio, width, and binding energy separation of approximately $6 \mathrm{eV}$ [3]. By deconvolution, the composition of the film on Tube $\mathrm{B}$ after 90 days can be given as $\mathrm{Ni}, \mathrm{NiO}$, and $\mathrm{Ni}_{2} \mathrm{O}_{3}$ whose peak positions are centered at binding energy (BE) of 852.1, 854.5, and $855.8 \mathrm{eV}$ as demonstrated in Fig. 18b(i).

The composition of the inner layer of the corrosion product on Tube A after 30 days' immersion can be identified as $\mathrm{Ni}, \mathrm{NiO}$, and $\mathrm{Ni}_{2} \mathrm{O}_{3}$ whose peak positions are 853.5, 855.4, and $856.8 \mathrm{eV}$ after sputtering for $300 \mathrm{~s}$. However, only one compound of $\mathrm{Ni}$ can be distinguished for the inner layer of the corrosion product on Tube B whose peak position is $855.1 \mathrm{eV}$ assigned to $\mathrm{NiO}$ after sputtering for $300 \mathrm{~s}$ due to its lower content in the layer. In accordance with the depth profile analysis, intense $\mathrm{Ni}$ $2 p$ spectra for the inner layer of the corrosion product on the two specimens were detected after 90 days' immersion. This gives an indication of $\mathrm{Ni}$ enrichment in the layer as demonstrated in Fig. 18. The deconvolution of the $\mathrm{Ni}$ $2 p$ spectra after sputtering for $300 \mathrm{~s}$ from the corrosion product on Tube A gives two components whose peak positions are 852.2 and $854.9 \mathrm{eV}$ attributed to $\mathrm{Ni}$ and $\mathrm{NiO}$. Also, the deconvolution of Ni $2 p$ spectra of the corrosion product on Tube B after sputtering for $300 \mathrm{~s}$ reveals two components whose peak positions are 854.3 and $856.0 \mathrm{eV}$ assigned to $\mathrm{NiO}$ and $\mathrm{Ni}(\mathrm{OH})_{2}$, respectively. Furthermore, the inner layer of the corrosion product on the two tubes gives weak Ni $2 p$ spectrum lines after 180 days' immersion as shown in Fig. 19. This indicates depletion of $\mathrm{Ni}$ in the inner layer at longer immersion time. By deconvolution, the composition of the inner layer of the corrosion product on Tube A can be identified as metallic $\mathrm{Ni}$ and $\mathrm{NiO}$ whose peak positions are 852.4 and $855.2 \mathrm{eV}$, respectively, after sputtering for $300 \mathrm{~s}$. While for the inner layer of the corrosion product on Tube $\mathrm{B}$, the deconvolution reveals one component denoted as metallic $\mathrm{Ni}$ whose peak position is at $852.8 \mathrm{eV}$ after sputtering for $300 \mathrm{~s}$.

\section{Discussion}

\subsection{Effect of Flow Velocity on the Erosion- Corrosion Behavior of $90 \mathrm{Cu}-10 \mathrm{Ni}$ Tubes}

Flow velocity is one of the most important factors that affect the erosion-corrosion behavior of copper-nickel alloys. The freshly polished samples and the filmed samples after being immersed in natural seawater responded differently to the flow velocities selected in this work. The mixed potential theory can be used to explain the electrochemical behavior of the freshly polished samples, as other researchers do in studying the erosion-corrosion behavior of copper-nickel alloys [27, 28]. An ideal schematic mechanism of the corrosion process of the freshly polished samples in $3.5 \mathrm{wt} \% \mathrm{NaCl}$ solution at the stagnant condition and at different rotation speeds is proposed, as shown in Fig. 20. The initial positive shift of $E_{\text {corr }}$ at the rotation 

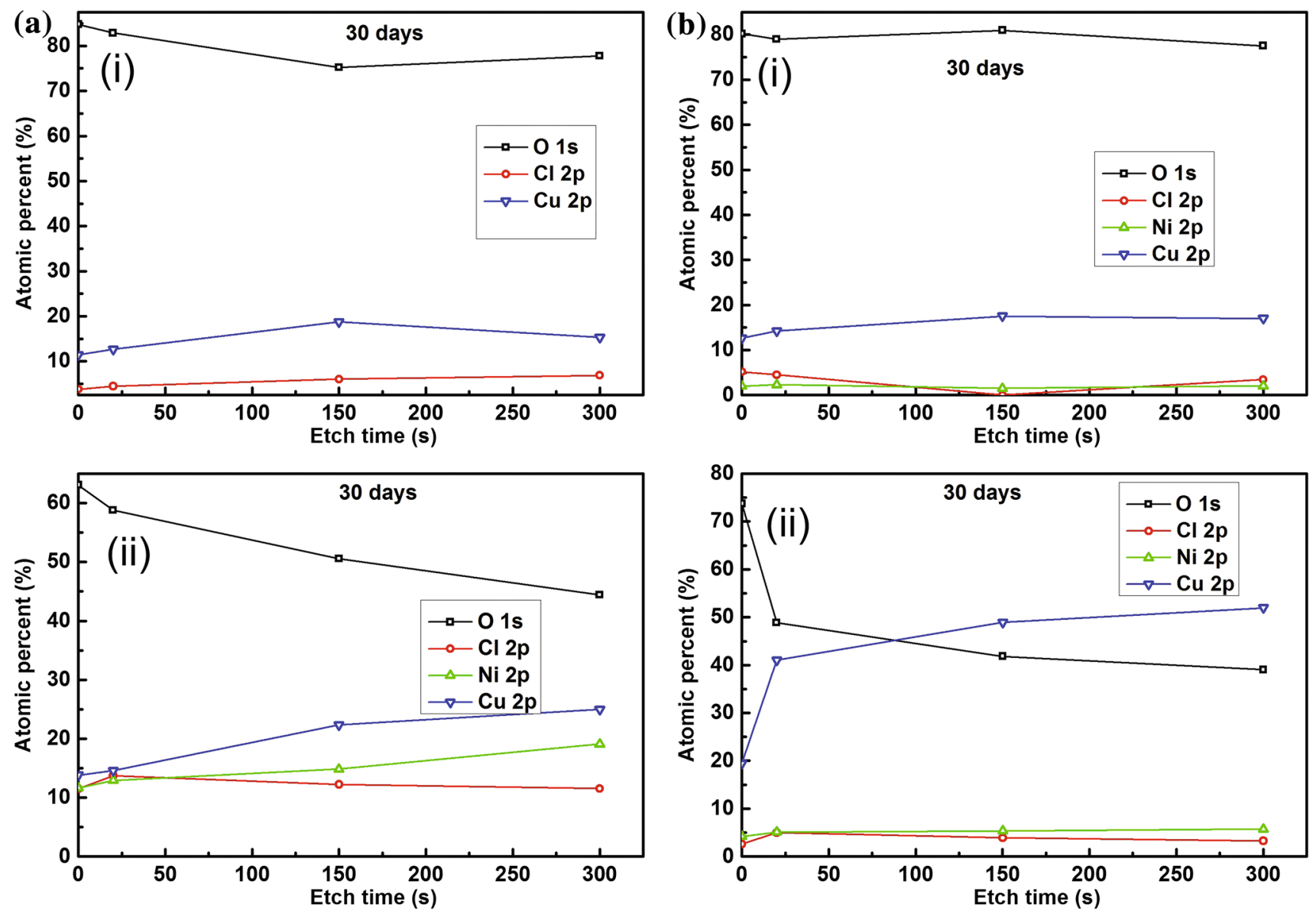

Fig. 14 XPS depth profiles of elements sputtered at the original surface (i) and at the slope (ii) between the exposed alloy substrate and the original surface formed by the scrapping process of the corrosion product film on Tubes A a and B b, respectively, after 30 days' immersion in natural seawater

speed of $400 \mathrm{rpm}$ can be explained by the accelerated cathodic reactions caused by the rapid $\mathrm{O}_{2}$ transport on the surface of the sample, as shown by the displacement from $P_{1}$ to $P_{2}$ in Fig. 20, which is based on the assumption that the cathodic process is controlled by the transport of dissolved oxygen and the anodic by the charge transfer process. Then, the fluctuation in $E_{\text {corr }}$ with further increase in the rotation speed (as shown by $P_{3}$ and $P_{4}$ in Fig. 20) is the result of the acceleration in both cathodic and anodic processes due to the heavier-weight role played by hydrodynamic shear force in washing off the corrosion product, suggesting that at higher flow velocities, the anodic process is mixed controlled. This is in line with the trend of corrosion current densities from the polarization curve fitting and $R_{\mathrm{p}}$ from the EIS fitting with increasing rotation speed, indicating that the corrosion process of the freshly polished samples was accelerated by the increasing flow velocity. Likewise, Naguib [29] postulated using mixed potential theory that the increased transport of $\mathrm{Cl}^{-}$or $\mathrm{CuCl}_{2}{ }^{-}$to or from the surface of the metal will accelerate anodic reaction while the increase of $\mathrm{O}_{2}$ supply will speed the cathodic reaction so that the corrosion rate will be increased when increasing the flow velocity. Combined with the trends of $E_{\text {corr }}, I_{\text {corr }}$, and $R_{\mathrm{p}}$ of the freshly polished samples with increasing rotation speed, it can be concluded that the flow velocity mainly enhanced the cathodic reaction when the rotation speed reached $400 \mathrm{rpm}$, and then both the anodic and the cathodic reactions were remarkably accelerated when the rotation speed reached 1300 and $2200 \mathrm{rpm}$.

It is well accepted that erosion-corrosion is a process in which electrochemical corrosion and mechanical damage take effect simultaneously. A competition between growth and damage of the passive film has been proposed to understand the erosion-corrosion behavior of different passive systems under different hydrodynamic conditions [30-32]. Sasaki and Burstein [32] used the competition mechanism to explain the shift of the open-circuit potential in the study of the erosion-corrosion of stainless steel under impingement by a fluid jet without sand. Likewise, Zheng et al. [30] explained the shift in open-circuit potential and corrosion current densities with the 

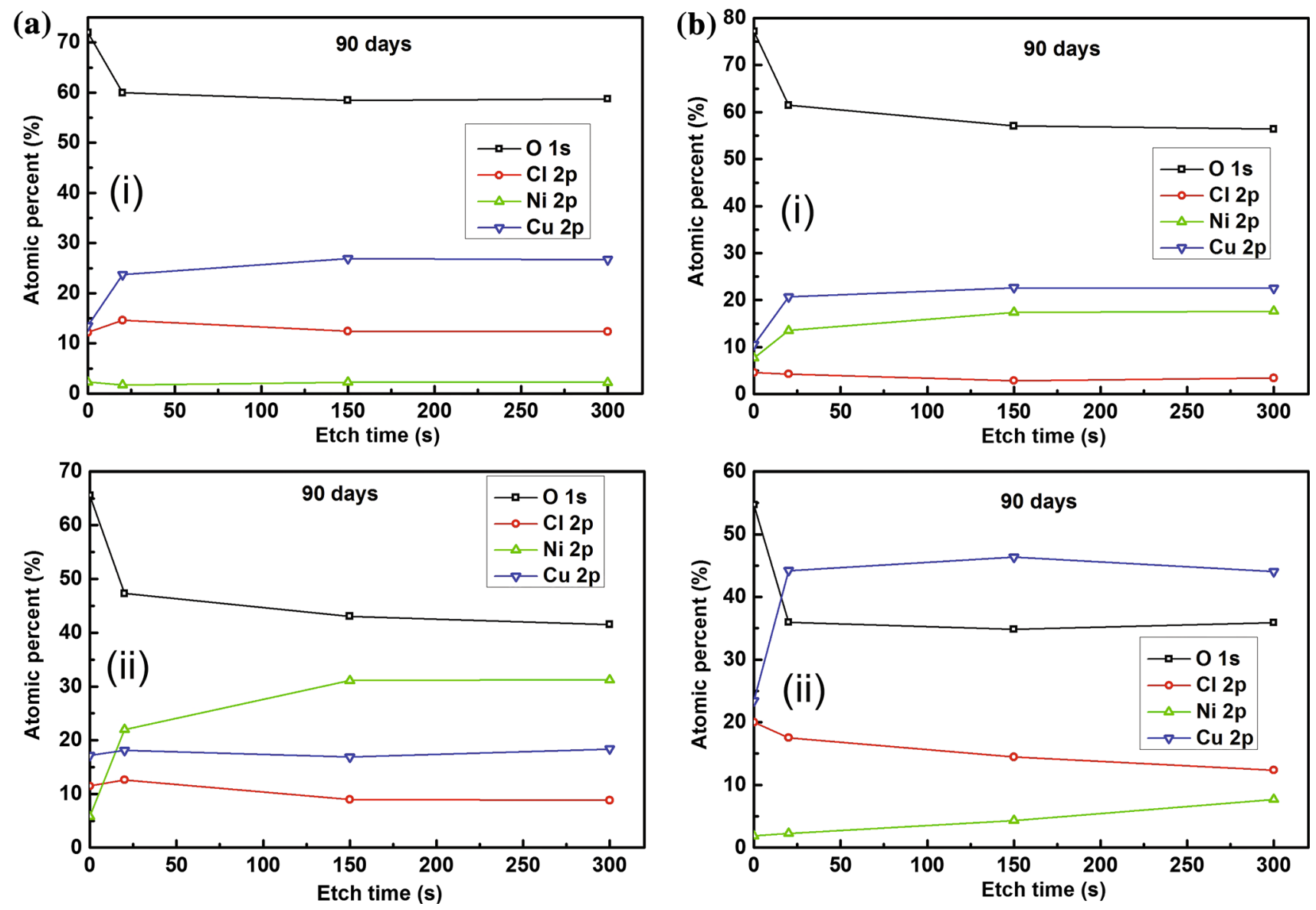

Fig. 15 XPS depth profiles of the elements sputtered at the original surface (i) and at the slope (ii) between the exposed alloy substrate and the original surface formed by the scrapping process of the corrosion product film on Tubes A a and B b, respectively, after 90 days' immersion in natural seawater

competition mechanism in determining the critical flow velocities of 304 stainless steel and a Fe-based amorphous coating. To sum it up, the open-circuit potential under erosion-corrosion shifted in positive or negative direction depending on the properties of the material/solution system. For passive systems, erosion-corrosion destroyed the passive film and exposed the bare metal to the corrosive solution resulting in a negative shifting. For the system that was not quite passive, erosion-corrosion accelerated the cathodic reactions and the passivation, thereby shifting the open-circuit potential in the positive direction.

Copper-nickel alloys in seawater or $\mathrm{NaCl}$ solution are not typically passive systems because their corrosion product films are much thicker and looser than the passive films on stainless steel and also evolve considerably with immersion time in seawater. However, the protectiveness of their corrosion product films is still higher than the rust on carbon steel. Thus, the effects of flow velocity on the erosion-corrosion behavior of the filmed samples of the two commercial $90 \mathrm{Cu}-10 \mathrm{Ni}$ tubes after being immersed in natural seawater are quite complicated, closely depending on the structure and property of the corrosion product film. A decreased $I_{\text {corr }}$ of Tube A and an increased $I_{\text {corr }}$ of Tube $B$ with increasing rotation speed were observed for samples after 30 and 90 days' immersion in natural seawater. This indicates that the binding force between the corrosion product film and the substrate of Tube A was strong so that the accelerated cathodic reaction caused by the rapid oxygen transport can promote growth and densification of the film, while the binding force between the corrosion product film and the substrate of Tube B was so weak that the film was destroyed or washed off by the hydrodynamic shear force before it could get repaired by the accelerated oxide growth as a result of the accelerated cathodic reaction. After 180 days' immersion in seawater, the corrosion product films with a sandwich structure on both Tube A and Tube B were so fragile that they were damaged or washed off by the hydrodynamic shear force caused by the increased rotation speed. 

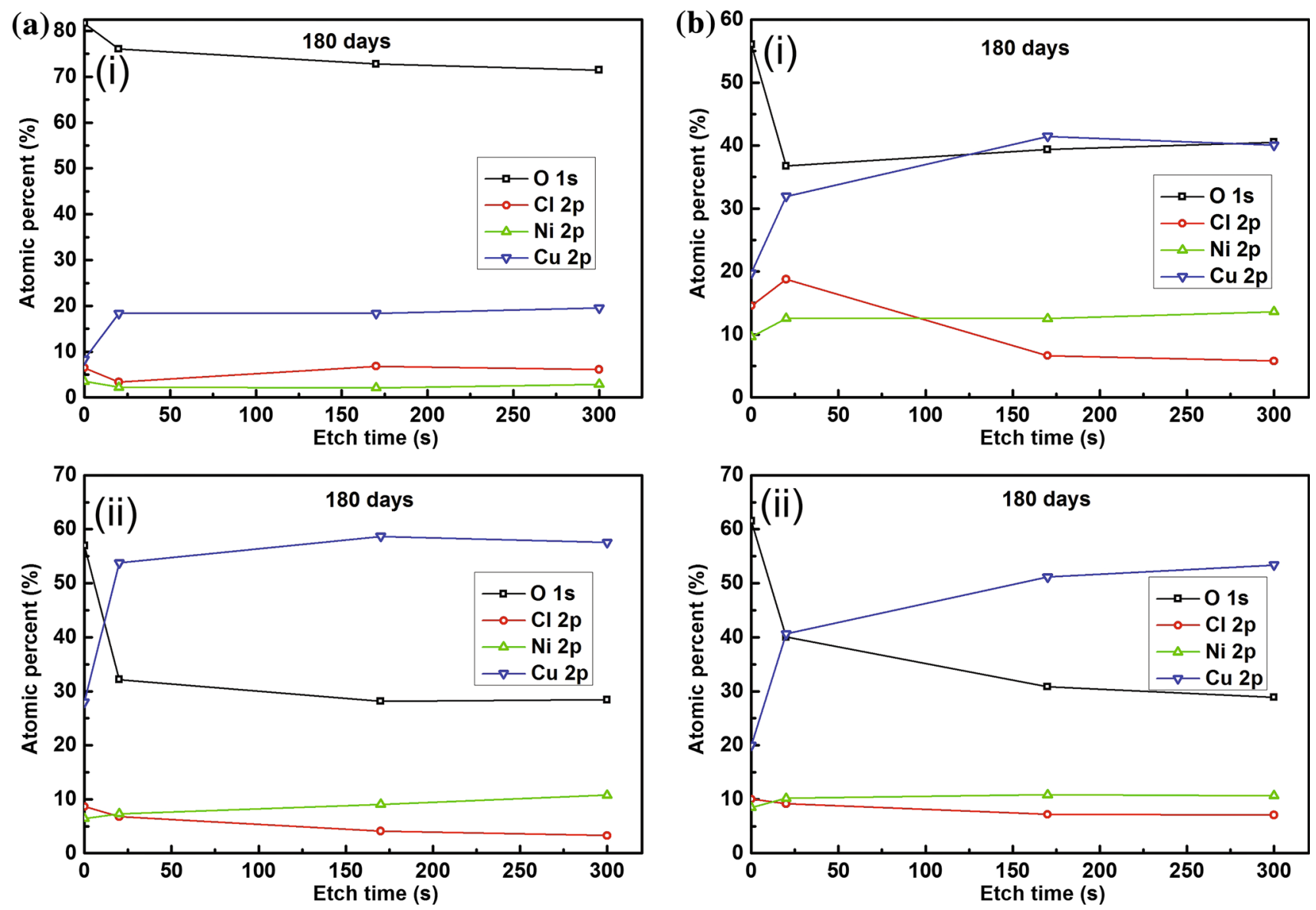

Fig. 16 XPS depth profiles of the elements sputtered at the original surface (i) and at the slope (ii) between the exposed alloy substrate and the original surface formed by the scrapping process of the corrosion product film on Tubes A a and B b, respectively, after 180 days' immersion in natural seawater

\subsection{Evolution of the Corrosion Product Film with Immersion Time in Seawater and Its Role in the Erosion-Corrosion Resistance of $90 \mathrm{Cu}-10 \mathrm{Ni}$ Tubes}

In 1920s, Bengough et al. [33] predicted that if the chemical nature of film/scale formation is considered only as a function of oxygen supply, a general stratification of a mature copper corrosion product film consisting of cuprous chloride, cuprous oxide, cupric hydroxide or oxide, and atacamite $\left(\mathrm{Cu}_{2}(\mathrm{OH})_{3} \mathrm{Cl}\right)$ or malachite $\left(\mathrm{CuCO}_{3} \cdot \mathrm{Cu}(\mathrm{OH})_{2}\right)$ from bottom to top in sequence should be observed. Although since then much effort has been made to clarify the composition and structure of corrosion product film of copper-nickel alloys formed in synthetic or natural seawater [10, 12, 28, 34], none of these studies has attempted to describe directly the evolution of the corrosion product film over a long-term immersion in seawater. So the picture of the corrosion product film of copper-nickel alloys in seawater is still far from clear or complete. This work tried to fill the gap by providing direct characterization of the corrosion product film.

Based on the morphologies displayed by backscattered electron images in Fig. 11 and the corresponding composition illustrated by the EDS line scan analyses in Fig. 12, a schematic diagram is drawn as shown in Fig. 21 to illustrate the structural changes of the corrosion product films formed on Tube A and Tube B through up to 6 months' immersion.

After 30 days' immersion, a corrosion product film with a three-layer structure was already formed on the surface of Tube B, as shown in Figs. $11 \mathrm{~b}$ and $12 \mathrm{~b}$ and illustrated in Fig. 21b. The inner layer is enriched with $\mathrm{Cu}$ and $\mathrm{O}$ and depleted of Ni probably as the result of selective corrosion of $\mathrm{Ni}$ (denickelification) [1,35]. This feature of enrichment in $\mathrm{Cu}$ and $\mathrm{O}$ and depletion of $\mathrm{Ni}$ in the inner layer was observed for Tube B throughout the 180 days' immersion period selected in this work, although the inner layer developed into a thick but hollow layer after 90 days' immersion, as shown in Figs. $11 \mathrm{~d}$ and $12 \mathrm{~d}$ and illustrated in Fig. 21d, and continued being oxidized into porous $\mathrm{Cu}_{2} \mathrm{O}$ 

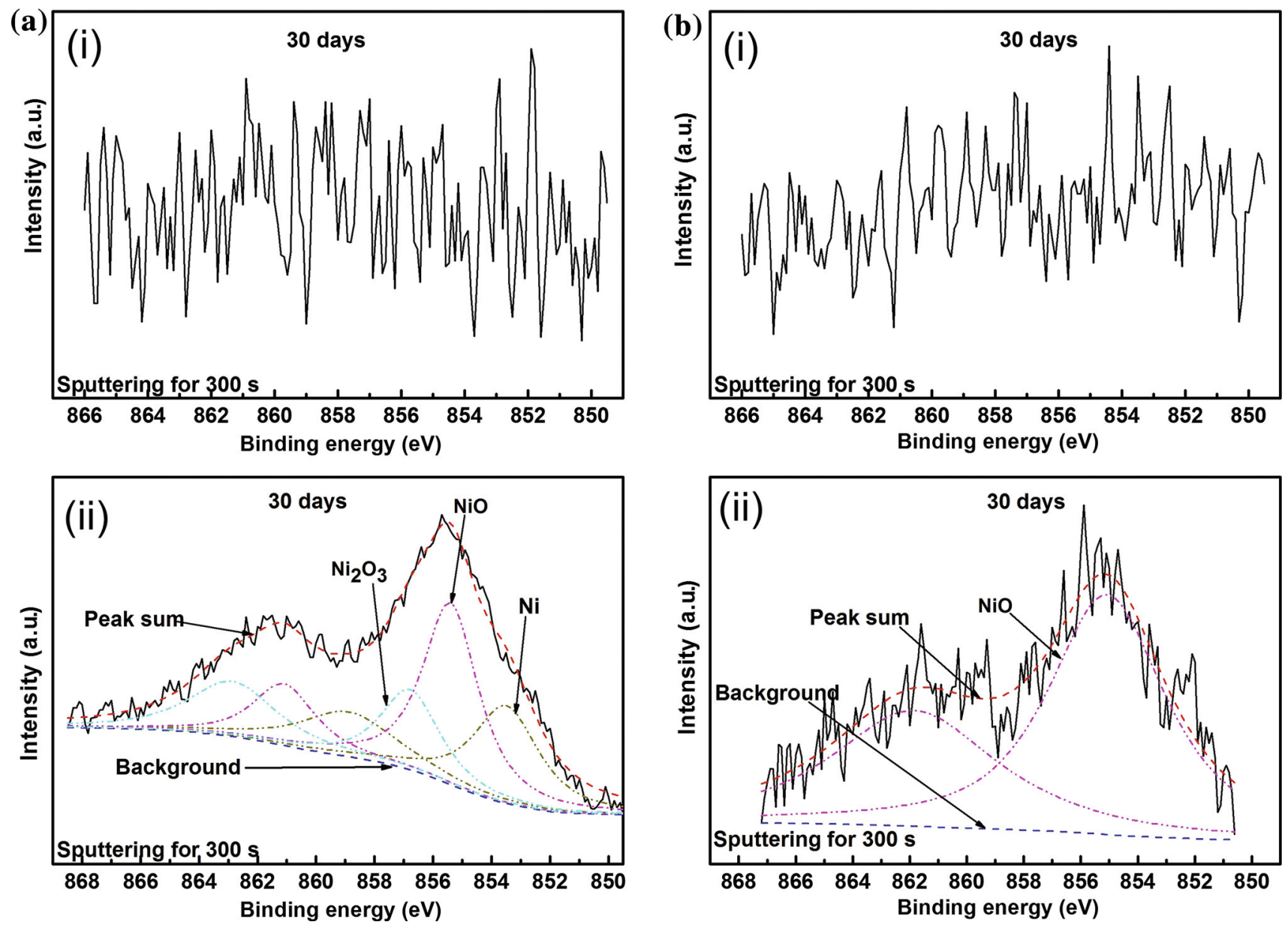

Fig. 17 XPS spectra of Ni $2 p$ sputtered for $300 \mathrm{~s}$ from (i) the original surface of the corrosion product and (ii) the slope between the exposed alloy substrate and the original surface after scrapping process of corrosion product film on Tubes A a and B b after 30 days' immersion in natural seawater

with some residual copper particles left after 180 days' immersion, as shown in Figs. 11f and 12f and illustrated in Fig. 21f. The feature of deposited copper was also observed in the outer layer of the corrosion film after 180 days' immersion, the mechanism of which has been fully explained in terms of the mixed potential theory by others $[12,36]$. The erosion-corrosion resistance of the film on Tube $\mathrm{B}$ is attributed to the middle layer which is supposed to be the protective $\mathrm{Cu}_{2} \mathrm{O}$ film doped with $\mathrm{Ni}^{2+}$, $\mathrm{Ni}^{3+}$, and probably $\mathrm{Fe}^{2+}$ according to the results of EDS, $\mathrm{XRD}$, and XPS, which is also in good agreement with previous reports [12, 24]. However, the erosion-corrosion resistance at higher flow velocity is also closely dependent upon the inner layer to which the $\mathrm{Cu}_{2} \mathrm{O}$ middle layer is attached. The $\mathrm{Cu}_{2} \mathrm{O}$ middle layer can survive at high flow velocity only if the underlying inner layer is compact and bonds firmly with the alloy substrate. However, the inner layer after 90 days' immersion is composed of the residual substrate depleted of $\mathrm{Ni}$ and the huge cavities partly filled with the porous $\mathrm{Cu}_{2} \mathrm{O}$. The binding force between the hollow inner layer and the substrate is so fragile that the middle layer together with the inner layer will be washed off directly by the hydrodynamic shear force, as demonstrated by the sharp decline of $R_{\mathrm{p}}$ in the erosion-corrosion test for the film formed on Tube B after 90 days' immersion.

The evolution of the corrosion product film on Tube $\mathrm{A}$ is quite different from that on Tube $\mathrm{B}$, reflecting the complexities of the corrosion product film on the copper-nickel alloy in seawater. Unlike the film on Tube B which deteriorates immediately with increasing flow velocity, the film on Tube A could grow and even get repaired with increasing flow velocity, as demonstrated by the trend of $R_{\mathrm{p}}$ for the film on Tube A after 90 days' immersion in Fig. 10. This can be attributed to its compact inner layer adjacent to the alloy substrate consisting mainly of $\mathrm{Cu}_{2} \mathrm{O}$ doped with $\mathrm{Ni}^{2+}, \mathrm{Ni}^{3+}$, and $\mathrm{Fe}^{2+}$ which can be observed throughout the 6-month period, while the layer with the same composition is observed in the middle layer above the hollow and discontinuous residual substrate for Tube B. This is 

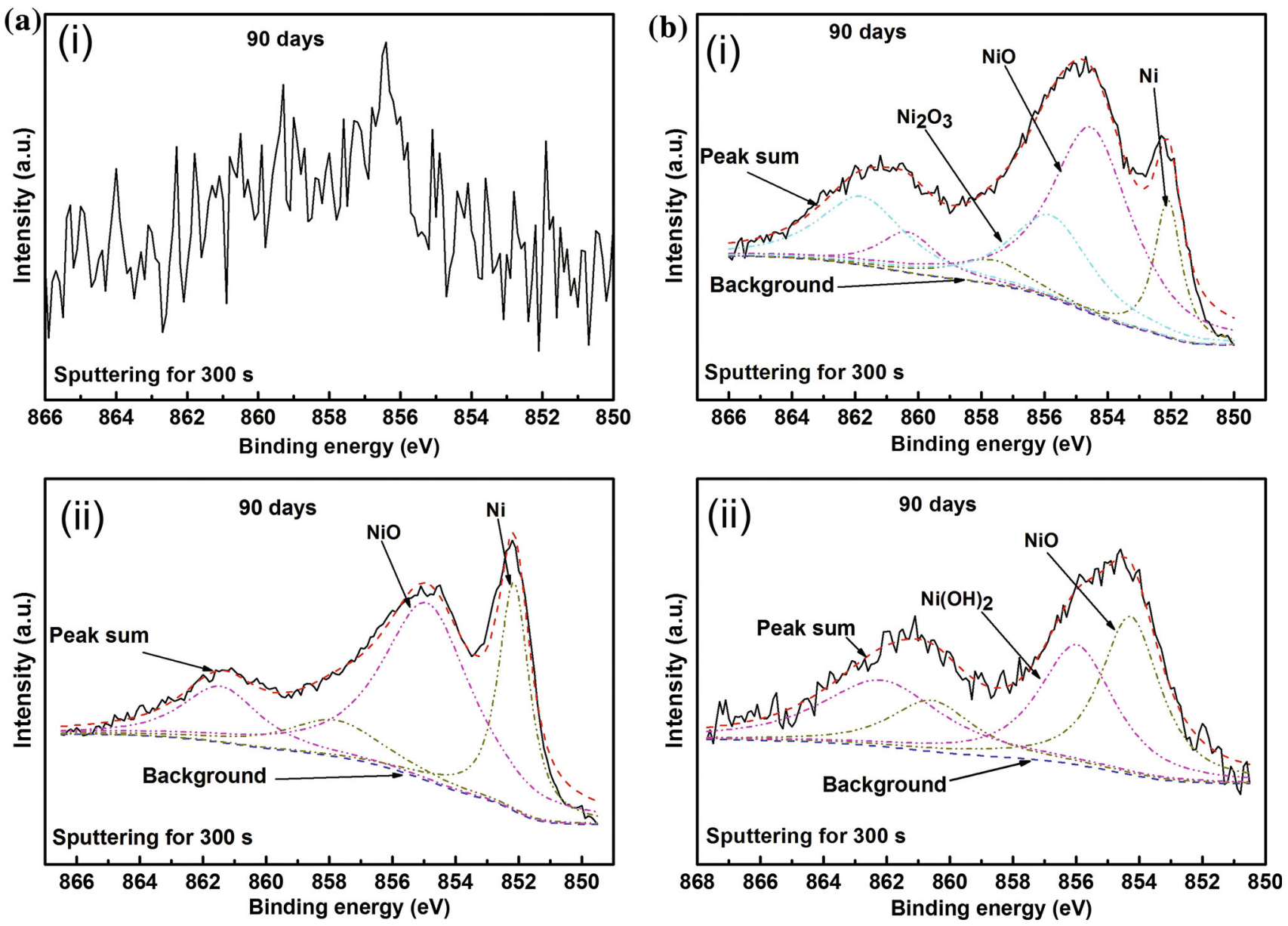

Fig. 18 XPS spectra of Ni $2 p$ sputtered for $300 \mathrm{~s}$ from (i) the original surface of the corrosion product and (ii) the slope between the exposed alloy substrate and the original surface after scrapping process of corrosion product film on Tubes A a and B b after 90 days' immersion in natural seawater

one of the major differences for the films on Tube A and Tube B. Another major difference is that the continuous residual substrate in the corrosion product film which is shown as the bright-white layer enriched with $\mathrm{Cu}$ and $\mathrm{O}$ and depleted of Ni in Figs. 11e and 12e was observed only in the film after 180 days' immersion for Tube A while the continuous residual substrate layer appeared throughout the 6 months' immersion period for Tube B, which indicates that the evolution of the corrosion product film on different samples is out of sync. Along with the $I_{\text {corr }}$ trend from polarization curve and the $R_{\mathrm{p}}$ trend from EIS, it is safe to say that the nature of the inner layer plays a crucial role in the erosion-corrosion resistance of the $90 \mathrm{Cu}-10 \mathrm{Ni}$ tubes at higher flow velocity. The film on Tube A possessing a compact and continuous inner layer of $\mathrm{Cu}_{2} \mathrm{O}$ doped with $\mathrm{Ni}^{2+}$ and $\mathrm{Ni}^{3+}$ could survive and even get repaired with the increased rotation speed even though the nonprotective outer and middle layers may be washed off by the hydrodynamic shear force. In contrast, the film on Tube B possessing a hollow and discontinuous inner layer degraded rapidly as the rotation speed is in spite of its quite good resistance at the stagnant or lower speed conditions. In general, however, the corrosion product films on both tubes deteriorated seriously when the immersion time was increased to 180 days.

The proposed schematic diagram of Fig. 21 can represent merely the structural changes rather than the formation mechanisms of the corrosion product films on Tube A and Tube B. The CuO layer in Fig. 21c is supposed to be the oxidation product of the porous $\mathrm{Cu}_{2} \mathrm{O}$ layer shown in Fig. 21a, and the transformation mechanism from $\mathrm{Cu}_{2} \mathrm{O}$ into $\mathrm{CuO}$ and $\mathrm{Cu}_{2}(\mathrm{OH})_{3} \mathrm{Cl}$ in the corrosion product films of copper alloys has been discussed in our earlier work $[12,37]$, though the XRD result in this work cannot support the existence of $\mathrm{CuO}$ in the corrosion product film. Although the formation mechanisms of the complex corrosion product films on both Tube A and Tube B are not fully understood in this work, we can conclude that the different erosion-corrosion resistances of the films on Tube $\mathrm{A}$ and Tube $\mathrm{B}$ are closely related to their different 

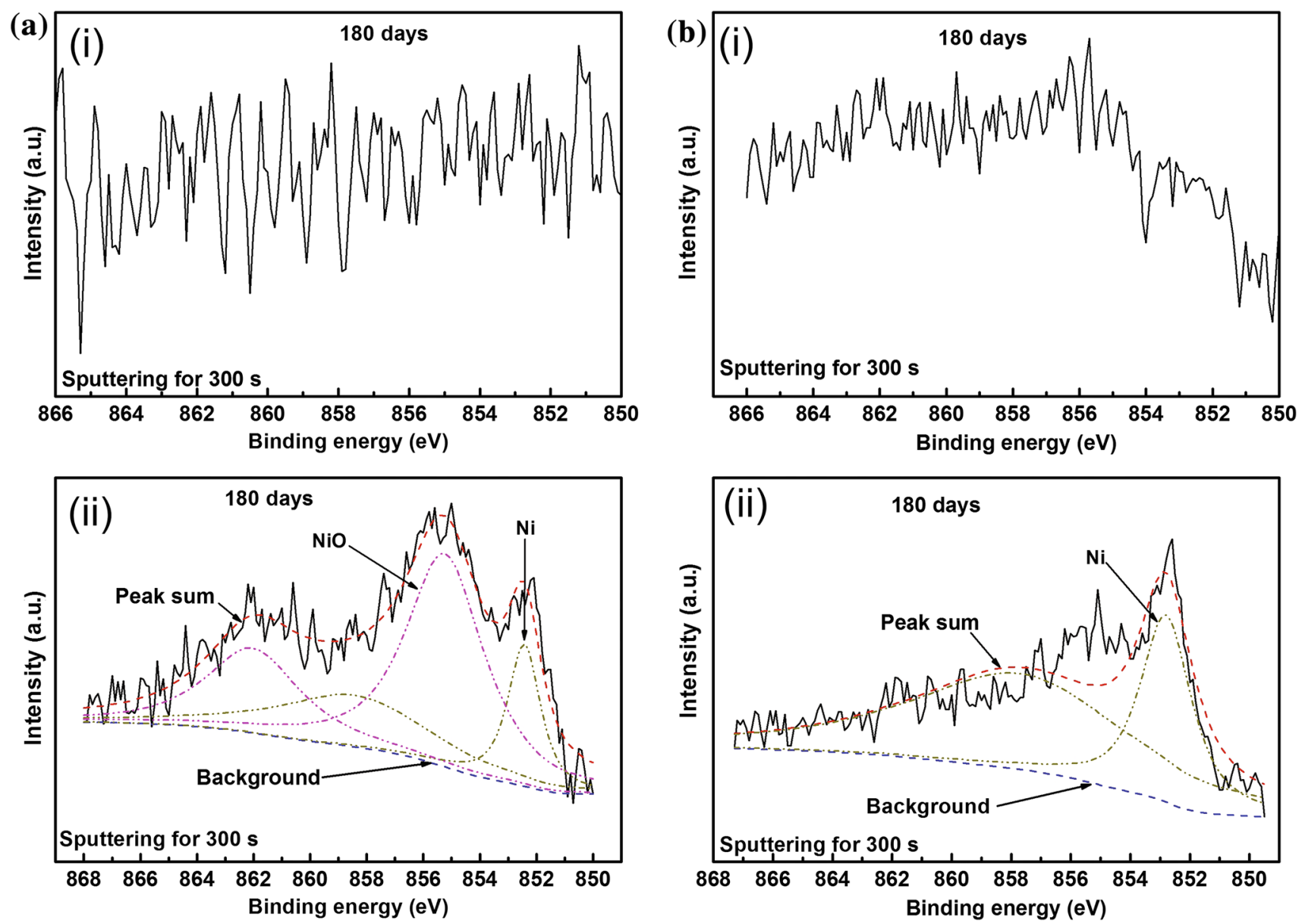

Fig. 19 XPS spectra of Ni $2 p$ sputtered for $300 \mathrm{~s}$ from (i) the original surface of the corrosion product and (ii) the slope between the exposed alloy substrate and the original surface after scrapping process of corrosion product film on Tubes A a and B b after 180 days' immersion in natural seawater

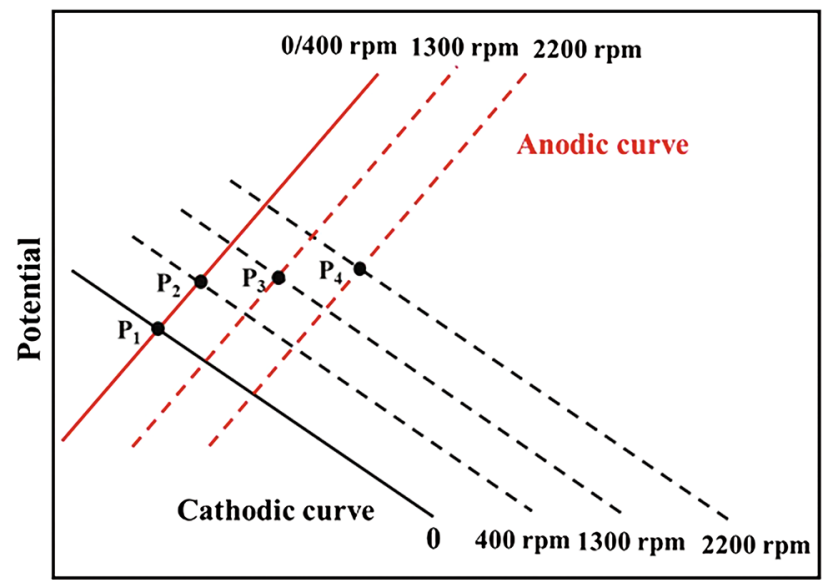

Current density

Fig. 20 An ideal schematic mechanism of the corrosion process of the freshly polished samples in $3.5 \mathrm{wt} \% \mathrm{NaCl}$ solution at the stagnant condition and at different rotation speeds

multilayer structures and that an inner layer of $\mathrm{Cu}_{2} \mathrm{O}$ doped with $\mathrm{Ni}^{2+}$ and $\mathrm{Ni}^{3+}$ which bonds firmly with the substrate plays a crucial role in the erosion-corrosion resistance of the $90 \mathrm{Cu}-10 \mathrm{Ni}$ tubes.

\section{Conclusions}

(1) For the freshly polished samples, the flow velocity mainly enhanced the cathodic reaction when the rotation speed reached $400 \mathrm{rpm}$, and then both the anodic and the cathodic reactions were remarkably accelerated when the rotation speed reached 1300 and $2200 \mathrm{rpm}$. This indicates that the cathodic process is controlled by the transport of dissolved oxygen and the anodic by charge transfer process at the stagnant or low flow velocity conditions, while the anodic process is mixed controlled at higher flow velocities.

(2) The corrosion product films formed on the two commercial $90 \mathrm{Cu}-10 \mathrm{Ni}$ tubes after being immersed in seawater for up to 6 months are of a complex 

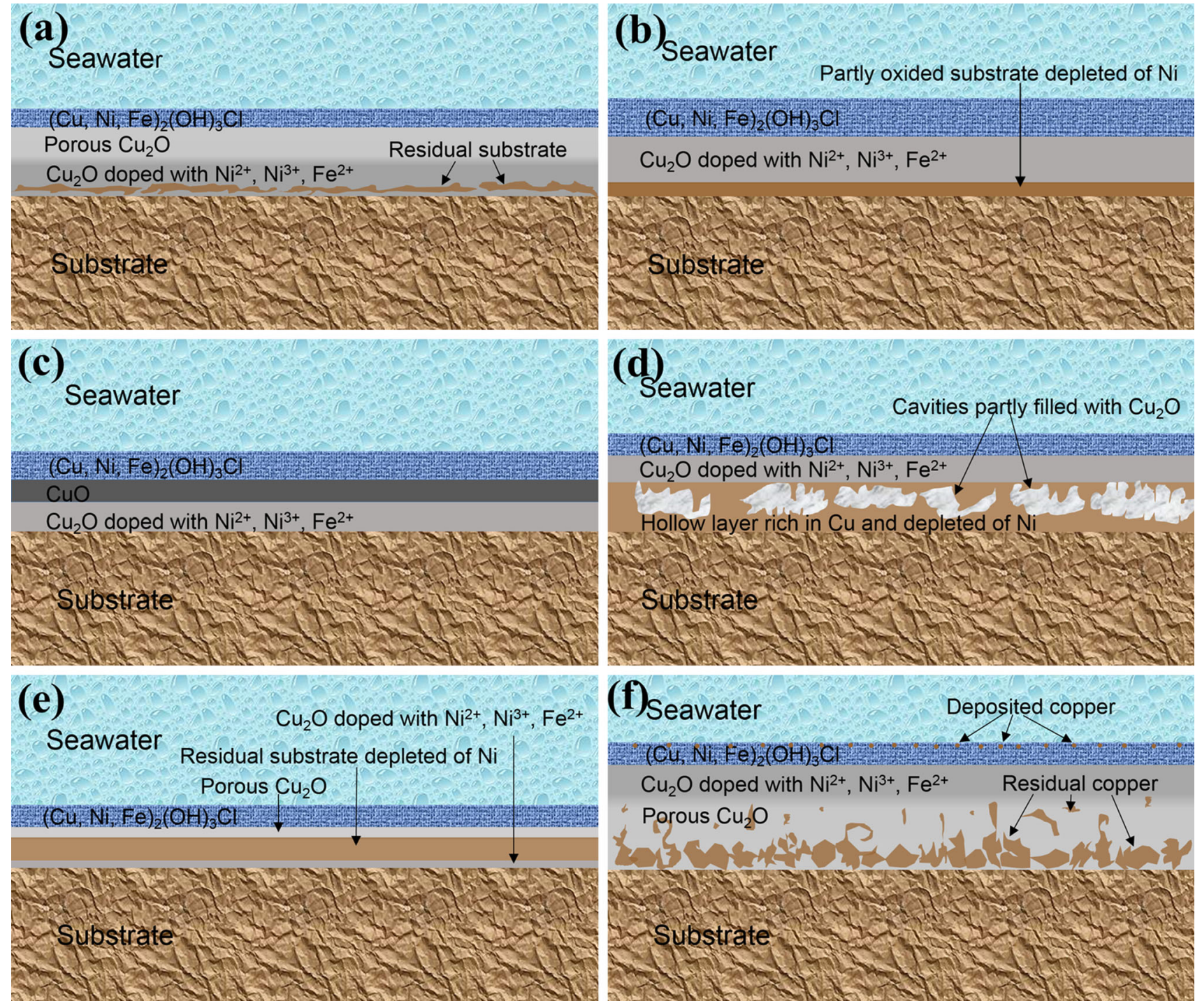

Fig. 21 Schematic diagrams of the structural changes of the corrosion product films formed on Tubes A a, $\mathbf{c}, \mathbf{e}$ and B b, d, f after 30 days $\mathbf{a}, \mathbf{b}$, 90 days c, d, 180 days' e, f immersion in natural seawater

three-layer or multilayer structure. The structural evolution of the films is out of sync for the two tubes. A continuous residual substrate layer depleted of $\mathrm{Ni}$ was observed in the inner layer of the films on Tube B after 30, 90, and 180 days' immersion, which was only observed in the film on Tube A after 180 days' immersion.

(3) The nature of the inner layer plays a crucial role in the erosion-corrosion resistance of the $90 \mathrm{Cu}-10 \mathrm{Ni}$ tubes at higher flow velocity. The different erosioncorrosion resistances of the films on Tube A and Tube B are closely related to their different multilayer structures. The film on Tube A possessing an inner layer of $\mathrm{Cu}_{2} \mathrm{O}$ doped with $\mathrm{Ni}^{2+}$ and $\mathrm{Ni}^{3+}$ which bonds firmly with the substrate can survive and even get repaired with increased flow velocity.
In contrast, the film on Tube B possessing a hollow and discontinuous inner layer composed of the residual substrate was degraded rapidly with increased rotation speed in spite of its quite good resistance at the stagnant or lower speed conditions.

Acknowledgements This work was financially supported by the National Natural Science Foundation of China (Grant No. 51601200) and the National Environmental Corrosion Platform (No. 2005DKA10400).

\section{References}

[1] F. Mansfeld, G. Liu, H. Xiao, C.H. Tsai, B.J. Little, Corros. Sci. 36, 2063 (1994) 
[2] W. Schleich, Typical Failures of CuNi 90/10 Seawater Tubing Systems and How to Avoid Them. In: Eurocorr, NACE. 1 (2004)

[3] S. Colin, E. Beche, R. Berjoan, H. Jolibois, A. Chambaudet, Corros. Sci. 41, 1051 (1999)

[4] K.D. Efird, Corrosion 31, 77 (1975)

[5] G. Kear, B.D. Barker, K. Stokes, F.C. Walsh, J. Appl. Electrochem. 34, 659 (2004)

[6] R.F. North, M.J. Pryor, Corros. Sci. 10, 297 (1970)

[7] W.B. Brooks, Corrosion 24, 171 (1968)

[8] A.M. Beccaria, J. Crousier, Br. Corros. J. 26, 5 (1991)

[9] A. Ma, S. Jiang, Y. Zheng, Z. Yao, W. Ke, Acta Metall. Sin. (Engl. Lett.) 27, 730 (2014)

[10] A.M. Beccaria, G. Poggi, P. Traverso, M. Ghiazza, Corros. Sci. 32, 1263 (1991)

[11] F.K. Crundwell, Electrochim. Acta 36, 2135 (1991)

[12] A.L. Ma, S.L. Jiang, Y.G. Zheng, W. Ke, Corros. Sci. 91, 245 (2015)

[13] S.R. Allahkaram, P. Zakersafaee, S.A.M. Haghgoo, Eng. Fail. Anal. 18, 1108 (2011)

[14] K. Chandra, V. Kain, G.K. Dey, P.S. Shetty, R. Kishan, Eng. Fail. Anal. 17, 587 (2010)

[15] O. Elragei, F. Elshawesh, H.M. Ezuber, Desalin. Water Treat. 21, 17 (2010)

[16] B.C. Syrett, Corrosion 32, 242 (1976)

[17] M. Metikoš-Huković, I. Škugor, Z. Grubač, R. Babić, Electrochim. Acta 55, 3123 (2010)

[18] T. Hodgkiess, G. Vassiliou, Desalination 183, 235 (2005)

[19] M.S. Parvizi, A.A. Aladjem, J.E. Castle, Int. Mater. Rev. 33, 169 (1988)

[20] C.A. Powell, H.T. Michels, Copper-nickel alloys for seawater corrosion resistance and anti-fouling-a state of the art review.
In: Paper Presented at the Conference of Corrosion NACE International, Orlando, Florida, 26-31 March 2000

[21] J.R. Macdonald, Impedance Spectroscopy: Emphasizing Solid Materials and Systems (Wiley, New York, 1987)

[22] S.A. Campbell, G.J.W. Radford, C.D.S. Tuck, B.D. Barker, Corrosion 58, 57 (2002)

[23] W.A. Badawy, K.M. Ismail, A.M. Fathi, Electrochim. Acta 50, 3603 (2005)

[24] P.K. Chauhan, H.S. Gadiyar, Corros. Sci. 25, 55 (1985)

[25] L. Babouri, K. Belmokre, A. Abdelouas, J.F. Bardeau, Y. El Mendili, Int. J. Electrochem. Sci. 10, 7818 (2015)

[26] B. Sun, T.Y. Ye, Q. Feng, J.H. Yao, M. Wei, Mater. Des. 8, $6029(2015)$

[27] G. Kear, B.D. Barker, K.R. Stokes, F.C. Walsh, Electrochim. Acta 52, 1889 (2007)

[28] R.J.K. Wood, S.P. Hutton, D.J. Schiffrin, Corros. Sci. 30, 1177 (1990)

[29] A.M. Naguib, Port. Electrochim. Acta 22, 301 (2005)

[30] Z.B. Zheng, Y.G. Zheng, X. Zhou, S.Y. He, W.H. Sun, J.Q. Wang, Corros. Sci. 88, 187 (2014)

[31] A. Neville, M. Reyes, T. Hodgkiess, A. Gledhill, Wear 238, 138 (2000)

[32] K. Sasaki, G.T. Burstein, Corros. Sci. 49, 92 (2007)

[33] G.D. Bengough, R.M. Jones, R. Pirret, J. Inst. Met. 23, 65 (1920)

[34] S.J. Yuan, S.O. Pehkonen, Corros. Sci. 49, 1276 (2007)

[35] P. Druska, H.H. Strehblow, Corros. Sci. 38, 1369 (1996)

[36] R.C.N. Liberto, R. Magnabosco, N. Alonso-Falleiros, Corros. Sci. 53, 1976 (2011)

[37] O.O. Ekerenam, A. Ma, Y. Zheng, W. Emori, J. Mater. Eng. Perform. 26, 1701 (2017) 